\title{
CASES OF METASTATIC CARCINOMA OF THE CHOROID AND IRIS \\ BY
}

\author{
C. H. USHER
}

ABERDEEN

SiNCE Devereux Marshall in 1897 collected from the literature 22 cases of metastatic carcinoma of the choroid and added two other cases of his own the number of published cases has largely increased, yet, carcinoma of the choroid cannot be regarded as a common affection. Lagleyze ${ }^{1}$ saw only one case in a total of 100,000 patients in an ophthalmic hospital during a period of thirty years. van der $\mathrm{Hoeve}^{2}$ states that his predecessor, Mulder, told him that he never saw a case of choroidal carcinoma during the 35 years he practised at Groningen, and was at the head of the institute for eye diseases. In adding three more cases to the already long list it is necessary at the outset to give some of the reasons for so doing. There is no unanimity of opinion as regards the possibility of diagnosing metastatic carcinoma of the choroid by ophthalmoscopic appearances alone, and as more attention appears to have been given to the pathological than to the ophthalmoscopical aspect of the subject, an account of the appearances presented by the fundus in two cases, observed repeatedly over a prolonged period from an early stage of the growth, may be worth recording and particularly because the tumours - there were five seen in three eyes-had so many characters in common. The importance of recognizing these tumours by their ophthalmoscopical appearance is increased by the fact that cases occur in which there is a latent primary internal carcinoma. In such cases a diagnosis of the tumour can be made only by means of the ophthalmoscope. As a rule the diagnosis of metastatic carcinoma of the choroid is simple. A large majority of the cases are in females and the primary growth is generally in the breast-64 times in 89 cases. In two of the three cases that form the subject of this paper the primary growth was not in the breast, and both cases were in males. Cases occurring in males are much less common than those in females-29 males in 102 cases. This small proportion of males to females was pointed out by Marshall, who also drew attention to the frequency with which the primary growth was situated in the breast, and to the short duration of life after the first onset of ocular symptoms, observations confirmed to-day by the larger figures now available. Metastatic carcinoma of the iris is evidently of unusual occurrence and further accounts of such cases are required. Such a tumour in the form of a single cyst is the explanation of a swelling that was seen during life in the iris of case $\mathrm{C}$. 


\section{Case A.-Latent primary internal carcinoma}

The following are the notes of the first case: William M., postman, age 36, came to the Aberdeen Royal Infirmary, on October 1, 1919, complaining of dimness of his left eye, with which he could see only parts of an object clearly. He had noticed the defect for two weeks and thought that his vision had not been quite right for five or six weeks. He said that he was in good health, slept well, had a good appetite, and had no headache. He denied having had any venereal disease. He had malaria in India in 1905, and influenza in Germany in 1918. He was a married man with 2 children, girls, aged eight and eleven years. His wife had had no miscarriage. He was the sixth in a sibship of seven, of whom all were alive and healthy, except the third, a brother, who was drowned. Both parents lived to over sixty. The father's death resulted from injury, but the cause of the mother's death was not known.

On examination there was no congestion of the eyes; corneae were clear; left pupil was a little smaller than the right one and contracted less well to light; anterior chambers were of equal depth; tension of the left eye was rather less than that of the right eye. R.V. $6 / 6, \mathrm{Hm}$. 1 ; L.V. 6/12, with plus 0.5 D. cyl. axis hor. $6 / 6$ not fully, and J. 1. The right fundus was normal. In the left fundus, above and immediately external to the fovea was a grey swelling with ill-defined margin, occupying an area about the size of two optic discs; its upper part was crossed by the superior temporal vein. The top of the swelling was focussed with plus $6 \mathrm{D}$., there were no haemorrhages. The optic disc was normal. The left field of vision was full and exhibited a small absolute scotoma up and in close to the fixation spot for a $10 \mathrm{~mm}$. square white object, and at the fixation point itself there was an absolute scotoma for a $2 \mathrm{~mm}$. red object. As the ophthalmoscopic appearance of the left fundus was equivocal, the case was referred to the medical side of the hospital. Professor A. W. Mackintosh, who admitted him to his ward and had him under observation for a fortnight, made a full examination of the case. The result of his examination, however, gave no clue as to what the fundus appearance might mean. When the patient was again transferred to the ophthalmic ward, apart from the ocular lesion, nothing abnormal could be detected. Although two Wassermann blood tests were negative mercurial inunction was given daily, and later on iodide of potassium with liq. hydrarg. perchlor., but with no good effect, for the fundus lesion continued to increase. His health was apparently excellent, his appetite good, and he had a healthy appearance. On November 25 he complained for the first time that he had been having pain in his left occipital region, and that now he had stiffness in his left arm, and a few days later there was pain in the region of the right scapula. But still nothing 
abnormal could be found in his lungs, abdomen, nose and adjoining sinuses, and blood; a tuberculin test gave a negative result. As the fundus lesion was extending and was probably a neoplasm, his left eye was excised on December 22. From this time until his discharge from hospital a week later the patient was despondent, though he made no complaint. He returned to hospital on February 23, 1920, and was readmitted to the medical ward. His wife stated that since returning home he had been tired, had had no appetite, and much thirst. He had been able to go out, but required a rest next day.as he felt unfit. He seemed very depressed and had pains in arms, shoulder, legs - everywhere - evidently very marked. He was sleepless, had much headache, and much constipation, much wandering. Professor Mackintosh found much depression, weakness, anaemia and wasting. Pulse poor and irregular. Nothing abnormal at bases of lungs. Urine: acid, specific gravity 1007 , no albumen, no sugar. Temperature $99.8^{\circ} \mathrm{F}$. Pain and tenderness in left sacro-iliac region and over the second lumbar vertebra, liver normal. Skiagrams of lumbar spine and skull showed nothing abnormal. The quantities of urine passed on February 24, 25, and 26, were 95, 90 and 86 fluid ounces respectively. February 26: "stool-no occult blood." March 1: "Leucocytes 7,500." March 3: "Blood pressure left arm $90 \mathrm{~mm}$. Hg." Urine: acid, specific gravity 1010, no albumen, slight diminution of chlorides, no sugar, deposit-actively motile bacilli with a few pus cells. Incontinence of urine for last few days. Patient unfit for further examination. March 4: Right fundus oculi examined, after dilatation of pupil, was normal. March 5: Much worse. Temperature $100.8^{\circ} \mathrm{F}$., pulse 110 , respiration 36. Much defective air entry, right base. Base of left lung behind has impaired note and some prolongation of expiration although breath sounds are better heard on left than right side. Death. Autopsy refused. Death certified-Tumour of eye, ? nature.* Diabetes insipidus. Pulmonary congestion.

The ophthalmoscopic examinations made from time to time subsequent to the first examination on October 1 are here for convenience of comparison recorded together.

October 20: The left fundus contains a diffuse grey homogeneous swelling about three times the size of the optic disc. Its summit, which is beneath the superior temporal vessels, is focussed with plus $7 \mathrm{D}$. The swelling is not pigmented. The field of vision is not quite full at the upper part of the nasal side. The paracentral absolute scotoma has increased in size. Vision is reduced to $6 / 12$.

October 27: The swelling has extended downwards and outwards

*The excised eye had not yet been examined microscopically. 
and is more mottled and appears to be less dense. Its summit is seen with plus $7 \mathrm{D}$. V. with plus $1.75 \mathrm{D} .=6 / 9$ not fully.

November 12: The grey swelling begins with a comparatively well defined edge where the superior temporal vein divides into two branches two-and-a-half optic disc diameters from the optic disc. The edge of the swelling at other parts is more indistinct. The upper part of the swelling is focussed with plus $8 \mathrm{D}$. The swelling does not involve the fovea, but passes external to it down to the inferior temporal vein. Just above this vein the swelling is focussed with plus $4 \mathrm{D}$., and the small vascular twigs passing upwards on to it are sharply defined. A mottled area adjoins the temporal edge of the swelling. There are no haemorrhages, or isolated white patches. Vision is $6 / 9$ not fully; contraction of the periphery of the field has extended at the upper part where it now includes the upper temporal portion, and the paracentral scotoma has increased in size.

November 20: The retinal blood-vessels above pass abruptly on to the swelling. There appear to be two actively growing areas, to judge from the greater degree of swelling at these parts, one is situated at the superior temporal vessels, the other in the region of the inferior temporal vessels, both are to the temporal side of an imaginary vertical line drawn through the fovea. The retina is detached at the periphery in the lower part of the fundus. At the macula there is no folding of the retina over the swelling. Vision is reduced to $6 / 12$ not fully.

November 28 :. The swelling has extended further up, well above the superior temporal vessels. The two most raised parts of the swelling are each focussed with a plus $8 \mathrm{D}$. The one is situated almost directly temporalwards from the fovea and is at a considerable distance from it, the other is not so far temporalwards and is higher up, about the level of the superior temporal vessels. In parts of the remainder of the affected region there is now more mottling. There is a small dark grey oval spot, with an arterial twig passing over it, situated at a short distance above the inferior temporal vessels. Fine vertical folds of retina are seen at the nasal side of the fovea; these form the nasal limit of the general opacity of the affected area.

December 14: There is no marked change in the left fundus since the last note was made. The optic disc is normal. There is an increase of opacity between the optic disc and fovea. The retinal vessels bend more abruptly at the site of the original opacity. This is also the case below at a part three optic disc diameters. along the inferior temporal vessels where the swelling is focussed with plus $6 \mathrm{D}$. Down and out from the general opacity is a mottled appearance. The dark grey spot noted on last examination is not visible. The detached retina at the lower part of the fundus is 
more marked and is tremulous. Vision is 6/36. Tension of the eyeball is normal.

December 17: The edge of the left optic disc is more indefinite than that of the right. The detachment of retina below is much more extensive and has crept up towards the macula and optic disc, and is very deep. The field of vision is almost abolished in the upper nasal quadrant, and to a considerable extent in the lower nasal quadrant. The upper portion of the temporal part of the field is

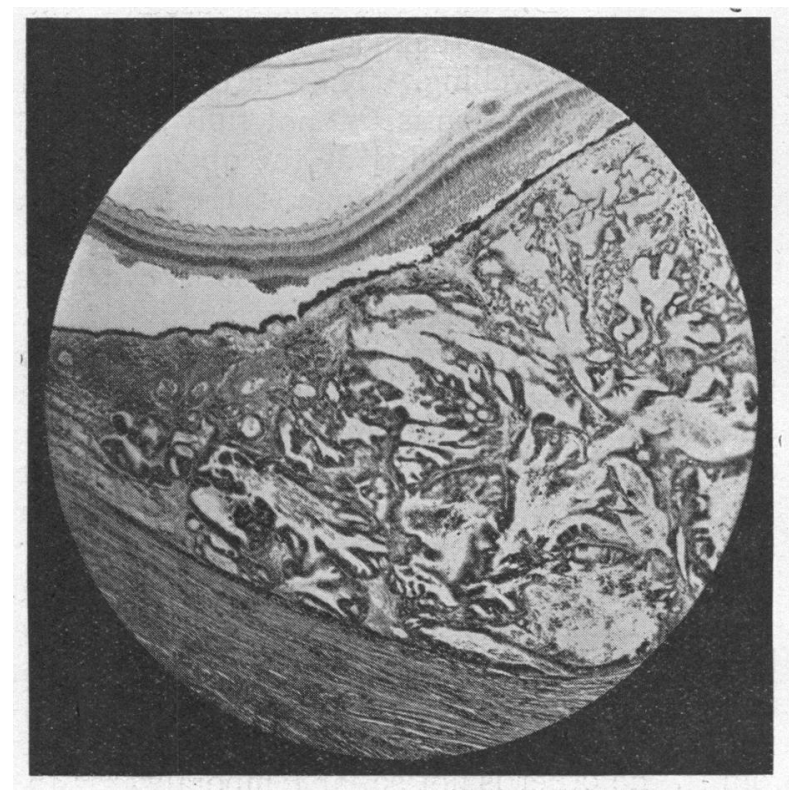

Fig. 1. CASE A.

Section of choroidal tumour from left eye of Case A., microphotograph $\times 25$.

To show the alveolar and papilliferous character of the growth.

much contracted, and there is some contraction of the lower temporal quadrant.

December 19: The top of the swelling is focussed with plus $10 \mathrm{D}$; retinal detachment below is still larger; no pigmentation of the growth, and no vessels of a neoplasm are seen. Vision is 6/36, and tension is normal. The right fundus is normal.

Examination of the excised eyeball : after excision the left eyeball was placed in $Z$ enker's fluid, then washed in running water and kept in 10 per cent. formalin. Later the eyeball was frozen and opened by an antero-posterior vertical section that passed through the optic disc. On macroscopical examination the nasal half was normal excepting the lower part where there was a shallow 
homogeneous yellowish mass behind the retina. In the temporal half a mass, having the same characters as that in the other half, occupied a corresponding situation ; it was not pigmented. Upwards from this was a raised and also unpigmented area that had not been divided by the section, and that presented four elevations or lobes. Microscopical examination shows a flat tumour situated in the posterior and temporal part of the choroid, having the characters of a papilliferous alveolar carcinoma (Fig. 1). Its greatest thickness is $3.5 \mathrm{~mm}$., and it invades the choroid for a distance of $14 \mathrm{~mm}$., the

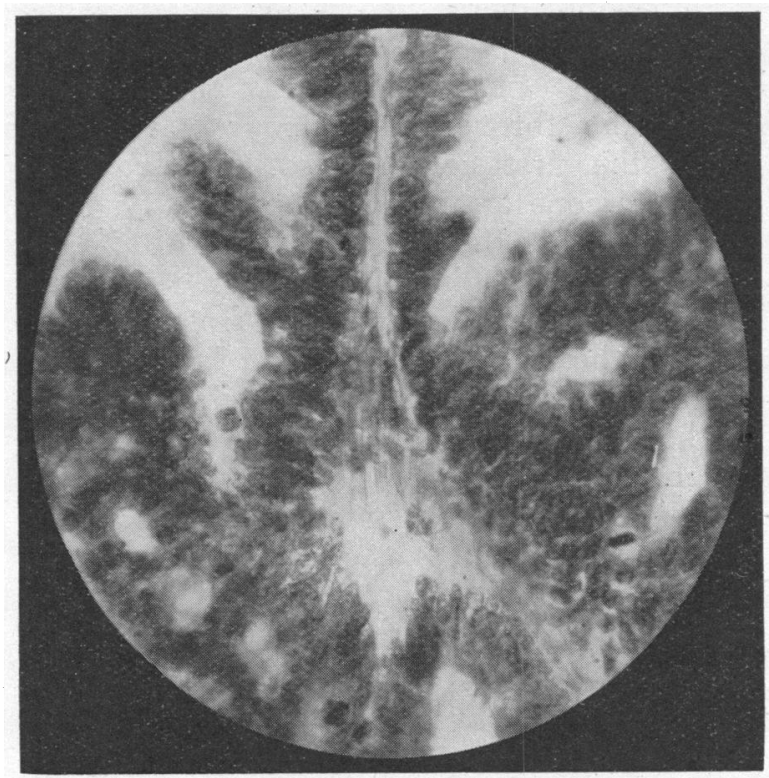

Fig. 2. CASE A.

From the same section as figure 1, microphotograph $\times 300$.

To show the columnar cells and the stroma in a papilla.

measurement being made from the upper to the lower edge of the growth. The tumour has no capsule, and consists of long columnar cells that form a single layer, and lie against a small quantity of stroma, which contains some pigment (Fig. 2). Though the epithelial cells are generally columnar, there is considerable variation in the length and shape of individual cells in some parts of the growth. In places the tumour cells show signs of degeneration, in other parts the cells are absent leaving only the stroma. The growth is alveolar, and papillae consisting of cancer cells and stroma project into the alveoli. There is an unstained (logwood and eosin) structureless material in some alveoli in which a number of separated and unstained epithelial cells can be recognized. In some sections 
darkly staining epithelial cells, singly, or in small groups, are present in the choroid at a considerable distance from the tumour. Any haemorrhage in the growth is quite insignificant. Cells from the growth are also present where some of the posterior ciliary vessels perforate the sclerotic, and appear in sections as isolated groups of cells. The form of some of these cells is polygonal. The hexagonal cells of the retina in front of the growth have become much depigmented and partially destroyed. The retina is separated from the growth by a structureless homogeneous substancealbuminous fluid. The separation is greatest at the lower part of the growth. The optic nerve and retina have not been invaded by the growth.

Comparison of the ophthalmoscopical appearances with the microscopical sections through the tumour of the choroid makes it probable that the first and greatest swelling that was seen with the ophthalmoscope at the upper part of the macular region was caused entirely by the choroidal growth, and that other prominent parts of the swelling that appeared later were to some extent caused by fluid separating the retina from the tumour, for the anterior surface of the tumour is even and has no local elevations. The mottled grey appearance that was seen on the surface of the swelling may be explained partly by differences in the degree of opacity that were possibly present in the retina at that area, and partly by the disturbance of pigment that has occurred in the pigment layer of the retina.

The diagnosis of metastatic carcinoma of the choroid is usually made without difficulty, for the primary tumour is generally evident, a mammary carcinoma in 71.9 per cent. of the cases-and there are. often widespread secondary growths, and obvious cachexia. There are cases on record, however, where the primary growth has been situated in an internal organ, in which the nature of the ocular lesion was not recognised clinically. In the whole of the literature Arisawa $^{3}$ found only one case, that of Gutmann's, in which at the time of enucleation of the eye there were no signs of the primary tumour. Arisawa's own case was that of a woman whose eye was excised for supposed sarcoma of choroid after a careful investigation of her internal organs had been made with a negative result. The patient appeared to be quite sound with the exception of general nervousness. A year after the ocular symptoms began she developed diarrhoea, anorexia, loss of flesh and weakness. At the autopsy rectal carcinoma was discovered. In the case now reported the excised eyeball was not examined until after the patient's death. As the eye contained a choroidal carcinoma, a latent internal carcinoma must have been present, though there was no autopsy to prove this. During life there was no reason to suppose from the man's general condition that he was suffering from carcinoma. He appeared to be 
generally in good health when examined on October 1 , and during the next two months he complained of nothing except defect of vision. Moreover, after repeated medical examinations nothing abnormal was detected. At the end of November, he had some occipital headache, stiffness of his left arm, and pain in his right scapular region, but none of these symptoms caused him much inconvenience. Though he slept well and had a good appetite he became nervous and despondent after excision of the eye.

In view of cases such as these in which localizing signs of a primary growth are absent for a long time after the onset of eye symptoms, it would be of value if a correct diagnosis of metastatic carcinoma of the choroid could be made by means of ophthalmoscopic examination alone. There are differences of opinion as regards the possibity of diagnosing these tumours by this means in absence of other symptoms. Swanzy and Werner ${ }^{4}$ state that it is impossible to distinguish choroidal sarcoma from choroidal carcinoma by the ophthalmoscope and Arisawa ${ }^{5}$ says that what clinically appears to be an undoubted primary intraocular tumour may be a metastasis from a latent carcinoma. According to $\mathrm{Fehr}^{6}$, on the other hand, who reported four cases in 1918, the ophthalmoscopic appearance is sufficiently characteristic even in absence of proof of a primary growth, although, in the very early stage or when there is total detachment of the retina, there may be difficulty. Oatman ${ }^{7}$ considers there is great uniformity in the description by different observers of the ophthalmoscopic appearances produced by early carcinoma of the choroid. Some of these descriptions, taken from his paper, are as follows: "small, round, yellowish deposits around the papilla" (Hirschberg); "grayish white, pinhead sized deposits in the macular region "(Schoeler and Uhthoff); "in the macular region a reddish - white discoloration, with scattered pigment" (Schapringer); " oval growth on temporal side of nerve, fading off into the surrounding fundus; dirty yellow colour, with scattered pigment" (Mitvalski); "sharply defined macular tumour, highest in the centre, and sloping to the periphery; light in colour"; (Wadsworth); " broad, flat, greenish-yellow deposit in the macular region" (de Schweinitz); "when first seen was diagnosed as central choroiditis" (Bentzon). In the left eye of Fehr's third case, small, white, ill-defined spots reminded him of fresh spots of choroidoretinitis and also of miliary tubercle. In the case now reported the growth was seen when it was small and was observed from time to time over a period of $2 \frac{1}{2}$ months. There was no yellow colour of the swelling as has frequently been noted in other cases, and there was no pigmentation, and no isolated grey or yellow spots. The ophthalmoscopic appearances did not resemble the coloured drawings of two of Fehr's cases, nor the drawing by Jacoby of Uhthoff' ${ }^{8}$ case where there were multiple isolated growths in the fundus; 
which appear to have had quite well defined edges and were pigmented. The clinical characters presented by the tumour, however, should certainly have suggested the possibility of a metastatic carcinoma of the choroid, namely, its situation at the posterior part of the fundus, the gradual shelving of the swelling to the normal fundus level, some prominences on the surface of the swelling, its ill-defined margin, its flatness, and the rapid rate of growth. Grey mottling at the edge of the swelling was also a marked feature,

In considering where the primary growth is likely to have been situated in this case in which there was no autopsy, reference is made to Gayet's ${ }^{9}$ case of choroidal tumour, where there had been stomach symptoms and a primary cancer of the stomach was found. The structure of the choroidal growth appears to have had some resemblance to that of the tumour found in the choroid of our case - see his Fig. 2. Kamocki ${ }^{10}$ believed that in his case of metastatic adeno-carcinoma of choroid, which resembled Gayet's case, the probable source may have been a carcinoma of stomach, but there was no autopsy. The patient had been apparently quite well when the eye was excised for supposed sarcoma of choroid, but shortly after leaving hospital he complained of illness and died not many weeks later. In Gelpke's ${ }^{11}$ case of medullary carcinoma of choroid there were long cubical cells and the primary growth was in the thyroid. In the case of Reis ${ }^{12}$ there was a papillary cysto-adenoma of choroid and the primary tumour was probably, but not proved to be, an intestinal cancer. A patient with adeno-carcinoma of the ciliary body seen by Paul ${ }^{13}$ had a large stomach cancer. During life blood had been found on microscopical examination in the stools, and there was resistance over the stomach. In Oatman' $\mathrm{s}^{14}$ case of cystic adeno-carcinoma of choroid the primary growth was in the liver. Although in the case now reported there is entire absence of proof as to the site of the primary growth it may well have been in the alimentary tract, possibly the stomach, for in latent carcinoma of the stomach there may be no symptons pointing to the stomach, and the tumour may be discovered accidentally after death. ${ }^{15}$

\section{Case B.-Primary mammary carcinoma}

The second case, though much less rare, presents certain points of interest. Both eyes contain metastatic growths, carcinomatous masses are present on the outer surface of each sclerotic, two growths occur in the choroid of the right eye, and both optic nerves are invaded by carcinomatous growths.

The case was that of a woman, age 35 , admitted to hospital on October 11, 1911. Her sight had been failing for five weeks before admission and she complained in addition of weakness and headache. Her right mamma was removed for carcinoma in January, 
1911. She had enlarged and hard glands in the right axilla, nodules in the abdominal wall and scalp; these increased and later were scattered over the surface of the body generally. She died on January 1, 1912. Secondary growths were found in the skin, scalp, pleura, lung, heart, liver, kidney, ovary, ileo-caecal valve, and brain. Specimens from this case were exhibited by Professor D. W. Finlay ${ }^{16}$, in 19i2, at a meeting of the Association of Physicians of Great Britain and Ireland, but the case was never published and for permission to do this now I am indebted to Professor Finlay.

A brief account of the condition of the eyes when examined clinically on two occasions is as follows:- Right eye, on October 17, 1911, had no perception of light, pupil did not contract to light, tension was normal, movements of eye were full, extensive funnel shaped detachment of retina, optic disc not visible; on November 14 the tension of this eye was +2 , the anterior chamber was shallow, eye movements full, no congestion of eyeball; with focal light a grey reflex with here and there a whiter part was seen in the pupil; on ophthalmoscopic examination a very feeble red reflex was obtained and that was only in the lower part of the pupil, no pigmentation visible, some pain in this eye, and for some days before death there was proptosis. Left eye, on October 17, 1911, had perception of light, the pupil contracted readily to light, tension was normal though rather soft, eye movements full, extensive deep detachment of retina at the lower part of the fundus; above the level of the optic disc the detachment was shallow, adjoining the optic disc were some retinal haemorrhages and exudation, fundus at upper part had a faint grey appearance; on November 14 the eye had no perception of light, the anterior chamber was shallow, tension normal, the pupil did not contract to light, with focal light the appearance of the pupil was similar to that of the right eye, no congestion of eyeball, eye movements full : on ophthalmoscopic examination a feeble red reflex was visible, four large bulging folds of detached retina enclosed a small reddish space, no pigmentation.

There was no difficulty as to the diagnosis of the ocular condition in this case. There was the history that a lump had appeared in the right breast in November, 1910, and that the breast had been removed in the following January, further, obvious secondary growths were present in other parts of the body. As mammary cancer is the most common primary lesion found in cases of metastatic carcinoma of the choroid, the site of the original tumour in this case together with the condition of the eyes which was in keeping with what is commonly found in choroidal carcinoma was highly suggestive that the eyes were affected with that form of tumour. The involvement of both eyes was another point favouring the diagnosis for in approximately a third of the cases of metastatic carcinoma of the choroid both eyes have been affected,-30 in 98 . 
The eyes were excised after death, hardened in 10 per cent formalin, subsequently frozen and opened by vertical sections in an anteroposterior direction, and embedded in celloidin.

Right eye, macroscopic examination: On the upper surface of the eyeball close behind the equator is an unpigmented very hard nodule with a smaller similar nodule close to its outer side; above the entrance of the optic nerve into the eyeball is a hard mass enveloping rather more than a half of the circumference of the optic nerve; several large tortuous, blood-vessels are seen on the eye in the region of the nodules; optic nerve is not thickened; anterior part of the eye is not invaded by the tumour; complete funnel shaped detachment of the retina is present; a firm pale brown growth extends from a short distance below the optic disc over the upper part of the fundus to the ora serrata, it has a well defined anterior margin, which is in a slight degree nodular, its outer surface is bounded by dense pale blue grey scirrhus-like tissue two or three times the thickness of normal sclerotic, at this part the sclerotic becomes indistinguishable; the inner surface of the tumour is lined by brown pigment-retinal pigment layer-the intraocular growth has a thickness of 1.5 to $2 \mathrm{~mm}$. which becomes less at the margin. Microscopical examination: a large flat carcinomatous growth occupies the choroid and is in some sections in two separate parts, or more probably there are two growths, the larger one being in the upper part of the choroid, the smaller one in the lower part; these flat neoplasms taper to a point where they approach each other, anteriorly they both extend as far as the ora serrata, internally they are limited by Bruch's membrane, externally by the sclerotic which in places has become very thin and has tumour cells invading it to a large extent; outside the sclerotic is a large mass of growth opposite the larger choroidal tumour, but none is present opposite the smaller growth; at the optic nerve entrance, processes project from the tumour into the nerve and are arranged parallel to the long axis of the nerve; these processes pass directly into the nerve at the optic disc; no tumour cells are present in the nerve sheath ; in transverse sections of the optic nerve at a short distance behind the eye there is no growth in the nerve, or its sheath; most of the growth consists of typical mammary carcinoma cells which in many places have an alveolar arrangement ; in some parts of the sections (stained with logwood and eosin) the cells are indistinct, have stained badly, and are evidently undergoing degeneration which explains a patchy appearance of the sections when seen with a low magnification. The extraocular part of the growth has more fibrous tissue than the intraocular part; brown pigment is present in small amount in the stroma of both parts of the tumour; small round inflammatory cells are numerous in some parts of the choroidal growth; the choroid has been largely replaced by the neoplasm. 
Left eye, macroscopic examination: On the lower posterior part of the outer surface of the eye is a nodular mass adherent to the sclerotic and encroaching on the optic nerve entrance and extending forwards for 10 or $12 \mathrm{~mm}$. It is unpigmented ; in section it is white and firm; large tortuous blood-vessels are present on the eyeball in its neighbourhood; optic nerve is not thickened; anterior chamber is very shallow; complete funnel-shaped detachment of retina with small haemorrhages in it; soft homogeneous tissue occupies the space between choroid and retina; occupying the lower part of the fundus is a firm, flat, pale brown tumour that extends from the ora serrata to some distance above the optic disc; it is thickest, $2 \mathrm{~mm}$., near the optic disc and gradually becomes thinner above and below ; its inner surface is sharply defined and is lined with brown pigment-retinal pigment layer; thickened sclerotic separates the pale brown intra-ocular growth from the white extra-ocular growth, which is thickest near the optic disc where it measures $\frac{1}{4}$ inch. Microscopical examination: a large flat carcinomatous tumour occupies the lower part of the choroid and extends from near the ora serrata, where it forms a wedge-shaped process lying between the sclerotic and Bruch's membrane, to a point a short distance above the optic disc where it terminates in a similar manner; no growth occurs above the optic disc on the outer surface of the eyeball, but below the disc growth has to some extent replaced the whole thickness of the sclerotic; the tumour cells have an alveolar arrangement and at the optic disc they extend directly from the intra-ocular tumour for some distance into the nerve as is shown in the micro-photograph (Fig. 3), but the nerve sheath is free from growth, and in transverse sections of the optic nerve at a short distance behind the eye there are no tumour cells present in either the nerve or its sheath; there is more fibrous tissue generally in this growth and less patchiness of staining than in that of the other eye; the tumour consists of one part, there is no suggestion of two growths as there is in the right eye, its inner surface is strictly bounded by Bruch's membrane, which in places is undulating, suggesting that it is ruptured, whilst on its outer side the sclerotic is invaded by carcinomatous cells; there are fewer inflammatory cells and less degeneration in this growth than in that of the other eye; pigmentation of the intra-ocular part of the growth is scanty, and there is no pigment in the extra-ocular portion; the iris angle is open.

The conditions present in this case are in the main not unusual and are in conformity with what has been described in most of the previously published cases. The growths are flat and situated in the choroid. Increase of intra-ocular tension was late in occurring. Death took place within a few months of the onset of the eye symptoms. What is less usual is the presence of a tumour in both eyes which occurs in about 30 per cent. of the cases, also, the 
presence in one eye of what appears to be two tumours, although this is not certain as serial sections were not made. In view of the aetiology of metastatic carcinoma of the choroid the occurrence of two tumours in one eye is not surprising, nor is it unknown. Cases of metastatic carcinoma of choroid extending to the outer surface of the eyeball are unusual, yet, cases such as the one now recorded in which an extra-ocular tumour had developed have been described, as in Lafon's and Oeller's cases. As regards direct extension of

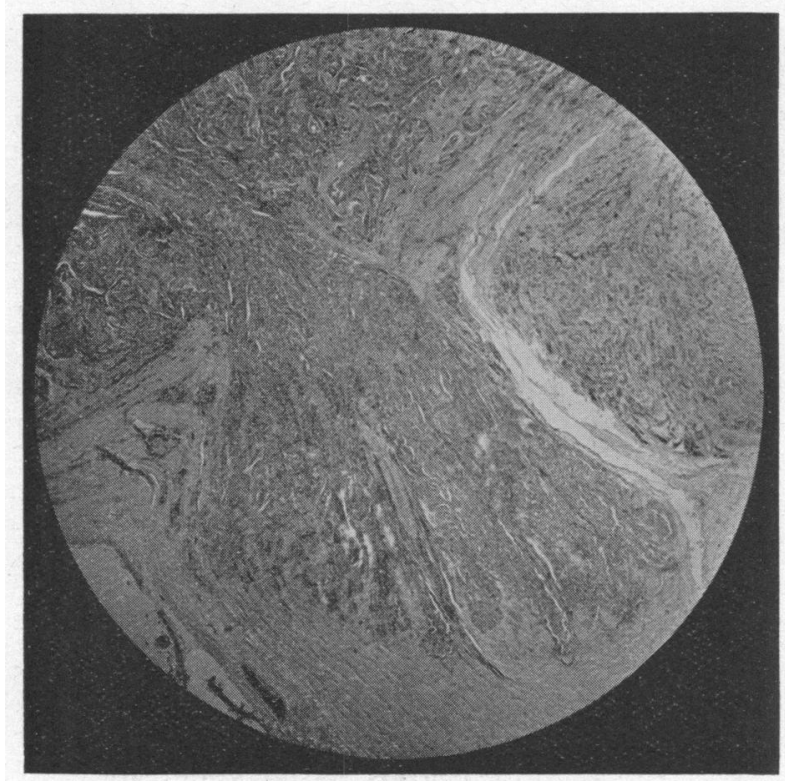

Fig. 3. Case B.

A section through the left optic nerve as it enters the eyeball in Case B., microphotograph $\times 13$.

To show the direct extension of the intra-ocular tumour for some distance into the optic nerve viâ the optic disc. The nerve sheath is present.

cancer cells from the intra-ocular growth into the nerve at the optic disc, Macmillan ${ }^{17}$. has recently published a comparable case, and v. Michel's $s^{18}$ second case appears to have had the optic nerve attacked by the tumour from the optic disc in a similar manner. Parsons ${ }^{19}$ states that extension to the optic nerve takes place by way of the lymph paths. The growth is deposited in the vaginal and perivascular lymph spaces and the nerve is rarely, if ever, attacked in continuity, the choroidal growth always stopping short at the edge of the optic disc. 


\section{Case C.-Separate carcinomatous growths in iris and choroid}

The third case, John M., aged 48, a tailor, came to the ophthalmic department of the hospital, on March 31,1922, complaining of defective sight in his left eye which he had noticed for the first time ten days previously. A black spot had also been present in the same eye for twelve months and was getting larger. His health had been good until three months ago when he became hoarse, and six weeks later he began to feel weak and soon afterwards found that he was losing weight. There had been no pains or discomfort anywhere in the body, no breathlessness and no dysphagia. He had had venereal disease twenty years ago, a nodule on the penis, but no secondaries as far as he knew. He was married, had eight of a family, no deaths had occurred and there had been no miscarriages. .He had three brothers and three sisters all in good health, a brother died at 56, of intestinal haemorrhage. Wife, aged 40 , was alive and well. His father died at 73 , and his mother at 70.

Ocular examination :-Right eye V. 6/6, Hm. 0.5. D., P. circular, contracts to light, T. n. media clear, fundus n. Left eye V. $=$ fingers at 2 feet, $P$. circular, contracts to light, T. n., some distended anterior ciliary vessels present. The iris in its lower part has a well defined swelling situated between the pupil and the ciliary attachment of the iris. The swelling is black excepting the edge, which has the same colour as the rest of the iris, namely, blue-grey with scanty stroma pigment. The whole appearance suggests that there is a cavity with a narrowed entrance. The black part of the swelling, measuring $4 \mathrm{~mm}$. and representing the entrance, becomes a bright red on transillumination. A grey swelling extends from a short distance below O. D. downwards and outwards for three O. D. diameters along the inferior temporal vessels, which are pushed forwards; retina is not folded over the swelling and there is no pigmentation. The upper limit of the swelling just reaches the fovea, lower edge shows distinct mottling, highest part of swelling focussed with a plus $6 \mathrm{D}$. lens. A week later, April 7, the optic disc showed haziness of its edge down and out, but otherwise was normal. Highest part of swelling focussed with a plus $7 \mathrm{D}$. lens. The mottling is marked along lower edge of swelling and fades gradually into the homogeneous grey of the swelling, and in the other direction is clearly defined from the normal red ground of the fundus. Near lower periphery of fundus is a yellowish, roughly circular, pigmented spot $1 / 3$ the size of $O$. D. At a distance of 1 $\mathrm{O}$. D. diameter up and in from this spot is another small yellowish spot adjoining a retinal vein. The left field of vision is contracted at the periphery above, and there is an absolute central scotoma for a $10 \mathrm{~mm}$. white square. The field for red, a $10 \mathrm{~mm}$. square being used, is much contracted, especially in the upper part. The right field of vision for white is full. 
The case was seen six months ago, by Dr. H. E. Smith, because of something on the left iris that the patient had noticed for six months. On September 27, 1921, Dr. Smith noted in the left eye a "small cyst down out in iris nearer ciliary than pupillary border, circular, diameter roughly $1.5 \mathrm{~mm}$. Iris tissue is stretched over greater part; through cyst red reflex is obtained. Fundus normal. V. 6/6. The patient had noticed no change in the 'bubble' for some months, and he did not remember having injured the eye at any time with his needle. R. V. 6/6, T. n., fundus normal."

General examination:-Lymphatic glands felt in axillae and groins ; from a hard gland on right side of neck at level of upper part of thyroid cartilage a chain of lymphatic glands with some induration of the right side of the neck extends vertically downwards nearly as far as the clavicle. Dulness of the right lung root is decidedly larger in area than on the left side. Breath sounds are weak over right lower lobe posteriorly, vocal resonance and tactile fremitus are also diminished over this area. Otherwise the lungs and the heart are normal. Nothing abnormal detected in the abdomen. Rectal examination negative. No occult blood in the stools. Urine : pale, acid, 1012, no albumen, no sugar, nothing in deposit except mucus. Testes and penis normal. Tongue normal. Paralysis of right recurrent laryngeal nerve. Skiagram and screen examinations of the chest show the root shadow of the right lung as very considerably increased. The diaphragm on that side has limited movement. There is no enlargement of the aorta.

It is not necessary to record particulars of his subsequent general condition. He gradually lost flesh, the liver became much enlarged, extending to the umbilicus. $\mathrm{He}$ was troubled much with breathlessness and some abdominal pain.

He died on September 2, 1922.

On April 17, as the fundus tumour had increased in size, the patient was anxious to have the eye removed, and the nature of the growth would be determined by excision, the left eye was excised, a small portion of the tumour was sectioned and found to be a carcinoma of the choroid.

Enucleation of an eye with carcinoma of the choroid according to Suker and Grosvenor frequently hastens the exitus. Marshall, on the other hand, believed that there was no reason why such eyes should not be removed; they are liable to attacks of acute glaucoma, and may, if they ulcerate, become extremely painful, whereas excision at an early stage involves practically no risk, and at least one source of discomfort is done away with, while the patient loses but a useless organ. There is certainly no reason to suppose that the death of case $\mathrm{C}$ was in any way hastened by the enucleation of his eye. Although not visible on ophthalmoscopic examination 
it is likely that carcinoma cells were already deposited in the choroid of the right eye at the time the left eye was excised, and only became manifest some time later.

On April 26, the right eye with V. 6/6 was again examined after homatropin. There was a large pale grey, homogeneous, raised area behind the inferior temporal retinal vessels focussed at its highest part with a plus $5 \mathrm{D}$. lens; it had an ill-defined edge. Except at the upper. part there was a broad mottled area adjoining the grey swelling. The length of the swelling was that of several optic disc diameters and its breadth was also considerable. Its upper end was two O. D. diameters from the O. D. The red reflex from the part of the fundus between the swelling and the $O$. D. was much reduced and there was a mottled appearance in this area. The shape of the swelling was similar to that of the tumour in the left eye. A second smaller swelling with the same characters as that of the first one was situated behind the superior temporal vessels far out. It was pale grey with mottling all over it as well as at its edge, and numerous minute, sharply defined, black, pepper-like spots were on it. Top of swelling focussed with a plus $5 \mathrm{D}$. lens. Edge of swelling not well defined. Fundus showed a good red reflex between the two growths. On May 5, the patient noticed defect of vision in this eye for the first time. V. $6 / 36$, with +2 D. $6 / 9$. When a strong light was used some indication of mottling could be seen on the lower as well as the upper swelling. None of the black specks of the upper swelling was in front of retinal vessels. The general colour of both swellings was pale grey, and not yellow. The grey opacity of the upper swelling was less marked than that of the lower. On June 16 , vision was reduced to $1 / 60$, tension was normal, both choroidal swellings had markedly increased in size. The upper one was focussed with a plus $7 \mathrm{D}$. lens, and the mottling was more marked than on last examination, but the pepper-like dots were rather less conspicuous. The lower swelling had extended well into the nasal part of the fundus and upwards close to the temporal side of the optic disc terminating at the upper and outer vicinity of the optic disc. The mottling was coarser than formerly and also in places darker. On the lower swelling were two small, oval, very dark bluish grey spots with sharply defined margins. Retina below was completely detached. On June 19, the optic disc had a good colour, but, its edge was hazy, and there was a small retinal haemorrhage just external to it. The grey mottled swelling adjoining the outer edge of the optic disc had extended upwards and outwards where it was continuous with the swelling at upper and outer part of macula. . The upper part of fundus was normal. Iris normal. T.-1 (fingers), Schiötz tonometer registered $11 \mathrm{~mm}$. of $\mathrm{Hg}$.: On July 27, the detached retina below 
obscured part of the optic disc and the lower part of the fundus up to the superior temporal vessels. No pigment was seen on any part of the swellings that still remained visible. On August 9, V. reduced to p. 1.

Pathological examination of the left eye.-The eyeball was placed in Zenker's fluid and later in 10 per cent. formalin. The eyeball which looked normal externally, was frozen and opened in a vertical antero-posterior direction. The section passed through a shallow pale grey growth which extended from the optic disc for a distance of $11 \mathrm{~mm}$. in the lower part of the fundus. The growth replaced

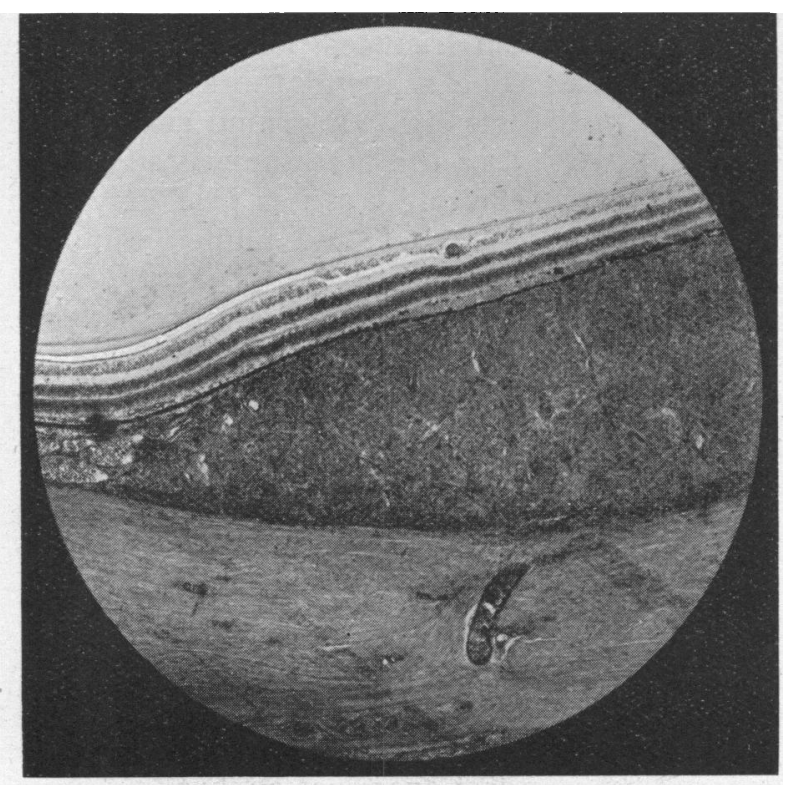

Fig. 4. CASE C.

Section of choroidal tumour from left eye of Case C., microphotograph $\times 25$.

To show tumour confined to choroid and its characteristic flat appearance.

the choroid, had an even anterior edge, and contained no visible pigment. With a convex lens a continuous layer of pigment was visible in front of it. The undivided portion of the growth included the foveal region and had an uneven surface. In the temporal half of eyeball at lower part there was a second swelling apparently quite independent of the choroidal growth just described. It had not been seen on ophthalmoscopic examination. Projecting from its anterior end was another much smaller elevation that reached the ora serrata, but apparently did not involve the ciliary body.

The lower part of the iris was partly replaced by a bluish jelly 
like mass which measured $2.25 \mathrm{~mm}$. antero-posteriorly and $3.5 \mathrm{~mm}$ in a direction from iris root to pupil. The mass touched the lens.

Microscopical examination.-The choroidal growth (Figs. $4 \& 5$ ) is confined to the choroid, and is composed of flattish cells. At the edge of the growth the tumour cells occupy the posterior layers of the choroid while the anterior layers are free, elsewhere the choroid is replaced by the growth which pushes Bruch's membrane and the retina forwards. Throughout the growth are septa with pigmented chromatophores which divide the tumour into compartments of

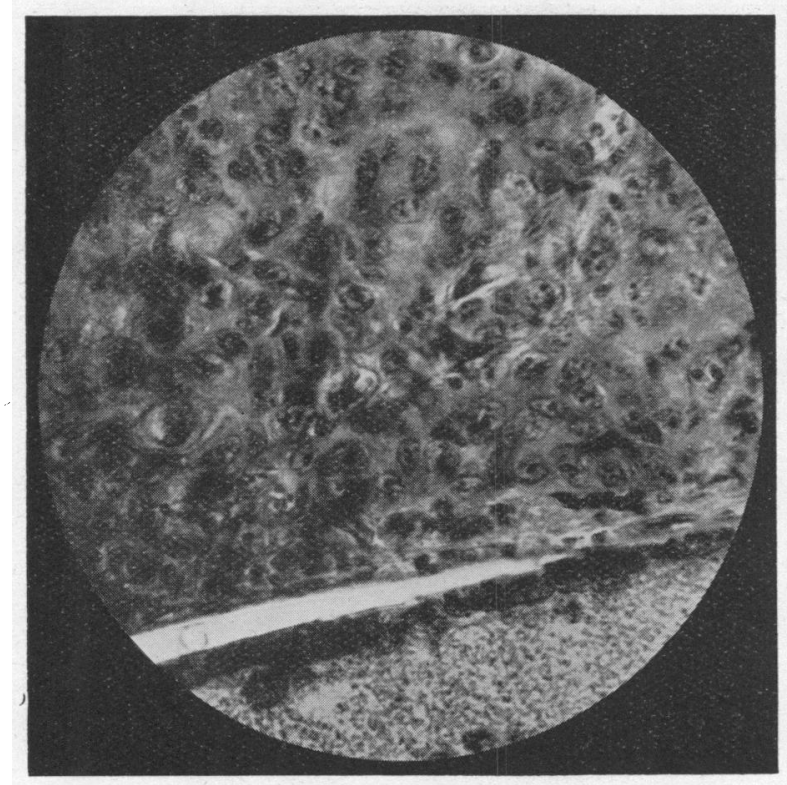

FIg. 5, CASE C.

From the same section as figure 4, microphotograph $\times 300$.

To show characters of tumour cells and their flat appearance.

various sizes and shapes. There is no lumen in any of the alveoli, which are packed with cancer cells. The tumour cells have large oval nuclei; mitotic figures are frequent. The cytoplasm of the cells varies in staining properties (logwood and eosin). In some cells are large circular unstained areas. A small round celled infiltration of inflammatory cells is present in some places at the edge of the growth. There is considerable alteration in the hexagonal cells of the retina in front of the tumour. Numbers of these cells are markedly depigmented, others have passed forwards singly, or in groups, and lie in the rod and cone layer, or where the retina has become separated by fluid they are found between the pigment layer 
and the bacillary layer of the retina. Bruch's membrane is clearly visible over most of the tumour and shows no evidence of rupture. The retina generally has its normal structure, excepting disturbance of the bacillary layer. The ciliary body contains no tumour.

The swelling at the lower part of the iris is a large cyst. Sections through its nasal portion (Fig. 6) show that the cyst is in the iris and that anteriorly it is bounded by iris stroma and posteriorly by the pigment layers of the iris. Temporalwards the cyst becomes

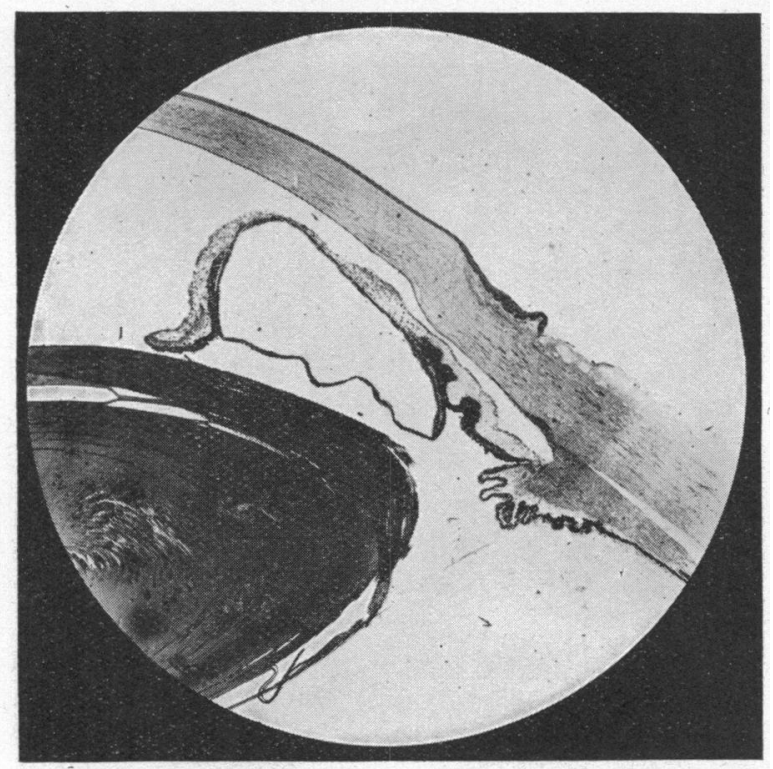

Fig. 6. CASE C.

Section through nasal portion of cyst in lower part of iris from left eye of Case C., microphotograph $\times 10$.

To show the cyst in iris bounded posteriorly by a layer of pigment and anteriorly by iris stroma.

larger and its wall thinner. The iris tissue in front of it becomes scanty, and the pigment layers posterior to it are attenuated. The sections show that at this level the iris angle is open both above and below, but still further to the temporal side, the cyst wall with a thin covering of iris stroma comes in contact with the posterior surface of the cornea and fills the iris angle below. At the iris angle the cyst wall becomes folded, and between the folds is a fine supporting structure with some blood-vessels. In sections still nearer the temporal side there is apparently no root to the iris, which is replaced by the cyst, which has again a thicker wall 
posteriorly with well marked pigment layers that represent the iris. There is no pigment layer in front of the cyst. In following serial sections in the same direction - temporalwards-(Fig. 7) the iris root gradually becomes re-established and a remarkable appearance is presented of a cyst without a pigment layer in the anterior chamber and a cyst completely surrounded by pigment situated behind and close to the iris. Consecutive sections show that what appears at this level to be two cysts is actually only one cyst. The intimate structure

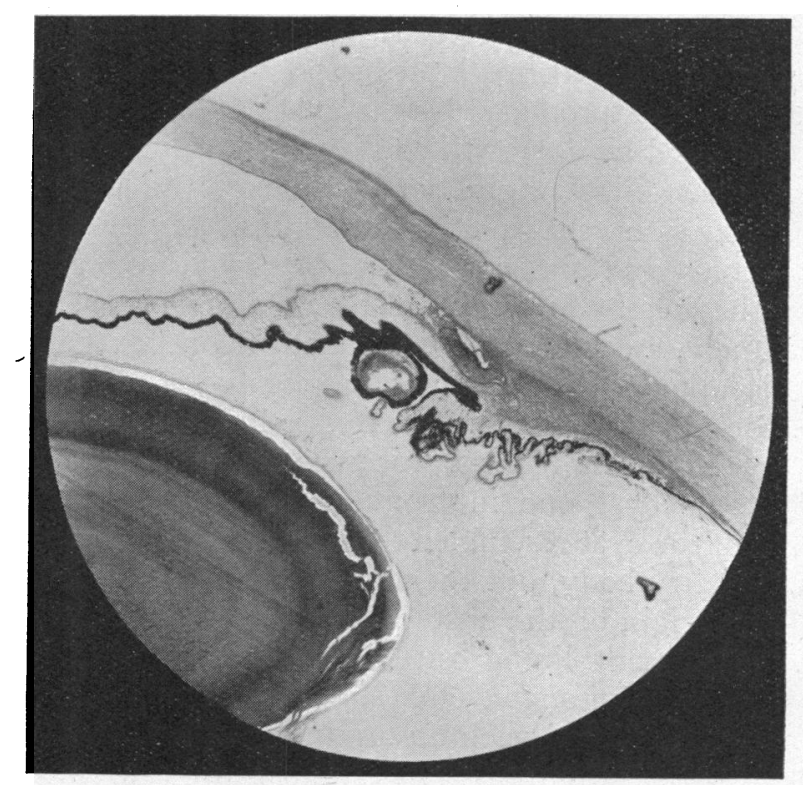

Fig. 7. Case C.

Section through temporal part of cyst in lower part of iris from left eye of Case C., microphotograph $\times 10$.

To show two outgrowths from the cyst, the one is surrounded by pigmented cells and situated posterior to the iris, the other without any pigment is in the anterior chamber. Ciliary body is not invaded by the cyst.

of the cyst consists of a lining composed of a layer of columnar epithelial cells which vary considerably in shape, some being long and narrow and frequently arranged in tufts, others are shorter and more cubical in form. Some that are well stained at their base are feebly stained at the part adjoining the contents of the cyst. The contents of the cyst consist of a homogeneous substance that stains blue with a faint red tinge with thionin, and red with muci-carmine, suggesting the presence of mucin. With both of these it is deeply stained. It contains a few cells. Two very small cysts, situated 
in the anterior part of the iris -stroma close to the anterior wall of the nasal portion of the large cyst, are found from an examination of neighbouring sections to be a single cyst, which is probably a small projecting portion of the large cyst. Some sections were lost at this part and the intercommunication was not found. The small cyst is lined with cells having the same appearance as those in the large cyst. None of the cells lining the walls of the cysts is pigmented. At no part is the ciliary body invaded. There is no evidence of inflammation in the iris or ciliary body. With regard to the origin of this large iris cyst, it appeared $a$ priori likely that it was metastatic, for it occurred in a man who had extensive carcinomatous growths throughout his body, and in both choroids, and the appearances produced by the cyst conform with those that would be produced by a growth arising and gradually extending in the iris stroma. This origin would explain the presence of the pigment lining on the posterior surface of the cyst in all of the sections and the absence of pigment from the anterior portion of the cyst. It would also explain what is seen in some sections, namely, a cyst devoid of pigment in the anterior chamber and what is apparently, though not actually, a second cyst completely surrounded by pigment situated behind the iris, for this appearance would result if two processes like fingers of a glove projected from the cyst one in front and the other behind the iris. Certain cells of the cyst resembled those that form the non-pigmented layer of the ciliary body, but the suggestion that these ciliary body cells were the origin of the cyst could at once be set aside for the cyst has no pigment lining anteriorly. A rare cyst reported by Coats in the Royal London Ophthalmic Hospital Reports, vol. 17, part 1, p. 143, 1907, had such an origin.- As the iris growth in the case under consideration originated apparently in the iris stroma there was the possibility of an implantation cyst to be considered. The clinical appearance of the cyst, its rate of growth, absence of a history or sign of a perforating injury, and the form of the cells do not favour such a possibility. Notwithstanding the marked difference in appearance between the solid choroidal tumour and the iris cyst, in view of the whole evidence, the latter is to be regàrded as a metastatic carcinoma,

The appearance of a cavity presented clinically by the iris swelling and the marked red reflex seen through the swelling are both satisfactorily explained by the thinness of the wall of the cyst, which reaches the anterior surface of the iris. There can be little doubt from what is known of the rapidity of growth of choroidal carcinoma, and from the history of this case, that the iris tumour was present before there was any choroidal growth. When seen on March 31, 1922, the patient had noticed defect of vision for only ten days and 
the choroidal tumour at this time was not large, whereas, the iris cyst had been seen by Dr. Smith six months previously, and the patient even a year before he came to the hospital had noticed a small black spot on the lower part of the iris which gradually increased in size. The iris growth was also present for some months before there were any symptoms of carcinoma in other parts of the body. The voice affection, his first symptom, occurred three months before he came to hospital.

Pathological examination of the right eye.-The right eye was excised six hours after death and placed in Zenker's solution and subsequently transferred to 10 per cent. formalin. After freezing, the eyeball was opened vertically by an antero-posterior incision. On macroscopical examination the eyeball looked normal externally. The interior of the eyeball anteriorly including the iris, ciliary body, cornea, and lens was normal and the anterior chamber was of considerable depth. Posteriorly, the retina was detached except at the ora serrata and the optic disc. A pale grey tumour occupied the choroid and extended from a point near the ora serrata in the lower part of the fundus backwards to the optic disc and then upwards and forwards for a considerable distance. The length of the tumour was $20 \mathrm{~mm}$., and it was shallow throughout. Its - greatest depth was well forwards in the lower part of the fundus where it measured $4 \mathrm{~mm}$. The tumour was lined on its anterior surface by a layer of brown pigment (the hexagonal cell layer of the retina) and its posterior surface adjoined the sclerotic, which was apparently intact. The anterior surface of the tumour was regular except at its most posterior part, where there were two or three small depressions and corresponding elevations. A homogeneous substance occupied the space between the retina and the retinal pigment layer. In the space formed by the detached retina posteriorly, and lens and ciliary body anteriorly, the vitreous was recognizable. Microscopically the tumour was similar to the choroidal tumour in the other eye, except at one part above where there were alveoli lined partly by columnar cells, but, for the most part, by cells similar to those in the solid part of the tumour. These alveoli contained a homogeneous substance that stained with thionin and muci-carmine in the same manner as the contents of the iris cyst in the left eye. The two different types of growth, therefore, found in the iris and choroid of the left eye are here represented together in a single tumour of the choroid.

\section{Professor Shennan's Report of the Post-Mortem Examination}

"Examination conducted six hours after death, Sept. 2, 1922.

The contents of thorax and abdomen were removed en masse, along with the cervical soft tissues and the structures forming the 
floor of the mouth. After partial dissection they were fixed in formalin-salt solution before further investigation.

The thyroid, at first sight, was of about normal size, with fairly regular contour, but on the surface of the left lobe and isthmus there were irregular yellowish-grey areas of firm infiltrating newgrowth, and streaks of similar material extended into the gland. The surface of the right lobe, especially in its lower part, was slightly nodular, and on section showed extensive infiltration and replacement by similar new-growth. This was directly continuous with a very firm mass-of dense scar-like consistence -behind and below it, which extended downwards in the angle between the innominate veins, and passed behind the superior vena cava and along the right bronchus into the root of the lung, where it infiltrated the walls of bronchi and blood-vessels. The root of the left lung was infiltrated in similar fashion. The bronchial and tracheal lymphatic glands, and the deep cervical chains of glands 'on both sides were enlarged and firm, and infiltrated with the new growth.

The oldest growth appeared to be in and below the right lobe of the thyroid. The tumour had invaded the posterior wall of the superior vena cava, and formed small low projections on its inner surface. It had also invaded the azygos vein, occluding it, and projecting from it into the superior vena cava.

In addition, tumour growth of scirrhus type, similar to that already described, was found on and under the pleura in small pearly masses, and in the liver where the innumerable masses varied in size from that of a millet seed to a mass $11 \mathrm{~cm}$. by $8 \mathrm{~cm}$. The larger masses in the liver which reached its surface, showed wellmarked umbilication. On section there was little degeneration and softening, but abundant formation of dense scar-like connective tissue. Similar firm creamy masses, mostly of the size of a hazel nut, were found in both kidneys, where they involved chiefly the cortex and base of the pyramid, having a certain resemblance in shape to infarcts of the organ.

New growth of another character was found in the posterior part of the lower lobe of the right lung. Here there was a mass for the most part of a greyish-brown colour, contrasting very strongly with the more or less pearly, firm, growth in the pleura and in the root of the lung. It was also softer and more spongy, with tiny nodules of the firmer growth embedded in it. It showed a tendency to softening in the centre, and to haemorrhage. It extended $2.5 \mathrm{~cm}$. into the lung; its greatest vertical diameter being $7.3 \mathrm{~cm}$. and its transverse diameter $4 \mathrm{~cm}$. This is the only mass of new growth in the body with these characters, with the exception of one of the smaller nodules in the left kidney.

The alimentary canal, spleen, pancreas and prostate showed 
no new growth; but in the upper posterior quadrant of the first part of the duodenum, just outside the pylorus, there was a small, irregular, recent, peptic, ulcer, with a perforation in its base, measuring $3 \mathrm{~mm}$. by $4 \mathrm{~mm}$., through which some of the contents had escaped, causing peritonitis. This ulcer was non-malignant in nature.

Two types of new growth, distinguishable by the unaided eye, were found in the thorax: and these were also different microscopically.

The older and harder parts of the creamy growth in thyroid, lymphatic glands, roots of lungs, liver and kidneys, resembled exactly scirrhus cancer, the stroma predominating over the cells, whereas the younger parts were like so-called "carcinoma simplex," the masses of epithelial cells being larger, and the stroma relatively diminished. The cells from mutual compression were angular or polyhedral, and a few were rounded or oval. In some parts they formed almost syncytial masses, the margins of the individual cells being indistinct, but for the most part the outlines of the cells were distinct, with narrow, ribband-like interspaces. From this appearance it was thought that they might be derived from squamous epithelium, but only in.a few places could appearances of "bridges" or "prickles" be made out with the oil immersion lens. The majority of the cells contained a colloid-looking droplet displacing the nucleus, and chromatolysis was a common feature. The naked eye appearances of the growth in the roots of the lungs was not that of a primary new growth. There was moderate narrowing of some of the bronchi, and invasion by new growth, and occlusion by organized thrombus, of some of the vessels in the same situation; but there was no evidence of origin either from bronchial mucosa or from mucous glands in the walls of the bronchi.

In the thyroid, on the contrary, there was some evidence of origin from the acini, and in the midst of some of the larger collections of cells in this organ, there were small masses of inspissated and calcified colloid, so that I have no doubt that the primary growth originated there.

The softer, grey-brown growth in the lower lobe of the right lung had the characters of a malignant papilliferous cysto-adenoma. The epithelial cells varied from short to long columnar and pear-shaped cells, varying considerably in size, and some of the larger pear-shaped cells possessed bloated, convoluted nuclei. The spaces were filled with thin, streaky, mucoid material, in which were embodied cast-off epithelial cells, a few red blood corpuscles and polymorphs. The cells in many cases contained material similar to that contained by the cells of the firm, creamy growth, and like it staining rose-pink with thionin. Moreover, the swollen and vacuolated nuclei of the larger cells resembled closely the nuclei of many of the cells of the 
other type of growth. In the lung, both to the naked eye and microscopically, the demarcation between the two types of growth was sharp. A somewhat similar structure was found in one of the nodules in the left kidney, but here there was not such a distinct alveolar arrangement.

This may be an example of variation in the type of growth derived from thyroid, but in the thyroid itself no new growth of cystic character could be found; or there is the remote possibility that the cysto-adenomatous growth was a local development in the lung. The appearance of two types of growth in the eye is especially interesting, because the choroidal mass resembles the scirrhus type of growth, whereas the cyst in the iris resembles closely the softer growth in the right lung and may have been derived by metastasis from it."

A growth in the iris of an eye that contains a carcinoma of choroid naturally leads to an enquiry respecting the clinical characters of metastatic carcinoma of the iris. Although metastatic carcinoma of the iris is much less common than metastatic carcinoma of the choroid, there are records of at least seven cases which include a description both of the clinical characters of the iris tumour and of the microscopical appearances.

Ewing ${ }^{20}$ describes a case in a woman, aged 32 . In her right eye at the outer part of the iris was a small greyish red tumour at the root of the iris. Microscopically, spaces were found filled with tumour cells and the pigment layers in the region of the tumour had partly disappeared. There was also present a metastatic carcinoma of the choroid and of the ciliary body.

Lagrange's ${ }^{21}$ case was a female, aged 48 , with a primary carcinoma of the breast. A carcinoma developed in the choroid of her right eye and a carcinoma in the iris of the same eye appeared clinically on surface view as a nodular, reddish, slightly raised neoplasm, but with sharply defined outline in the outer part of the iris. The iris angle was obliterated at the part corresponding to the neoplasm. The iris preserved its ordinary aspect except at the site of the growth. The eye was excised as it was glaucomatous and painful. It contained a choroidal tumour, which was quite independent of the iris tumour. The growth occupied the iris stroma and from there did not penetrate deeply the ciliary region. The iris tissue was infiltrated by epithelial cells, but no alveoli could be distinguished though these were present in the choroidal tumour.

Briehn's ${ }^{22}$ case was that of a female, aged 55, with primary breast cancer. At the end of August, 1901, there was a grey-red nodule the size of a pin's head on the temporal side of the iris in the right eye. It gradually enlarged and a second nodule appeared close below it. On the following Octobcr 24, when the eye was excised 
there was a lens sized yellow-grey nodule on the periphery of the iris, temporalwards, with small blood-vessels on its surface. A second nodule of the same nature lay close below the first one. Pupil zone was free of visible pathological changes. Pupil reacted promptly to light ; tension slightly raised; fundus normal. Left eye normal. Patient died on January 11, 1902. Examination of the excised eyeball showed that the ciliary body and two-thirds of the iris at one side of the sections were occupied by a continuous tumour formation. The tumour showed here and there an alveolar structure. There were epithelial cell nests. The cells were partly cubical, partly cylindrical, the nucleus was generally single and large; many cells showed mitosis; much necrosed tissue in the tumour.

Cutler's ${ }^{23}$ case was that of a female, aged 33 , with a primary breast cancer. On the temporal side of the left iris was a dull greyish mass slightly elevated, not vascular, and sharply defined, occupying about half the width of the visible iris. Microscopical examination showed a carcinoma in the ciliary body extending into the iris for an apparent distance of $3 \mathrm{~mm}$.

Paul's $\mathrm{s}^{24}$ case was in a male, aged 66 , with a metastatic adenocarcinoma of the ciliary body of the right eye. The primary growth was in the stomach. A reddish white, cone shaped tumour with numerous superficial vessels appeared at the inner lower quadrant of the right iris. It almost completely filled the iris quadrant, extended to the pupil, and inserted itself between the lens capsule and the posterior surface of the iris as small nodules the size of a pin head. Three weeks later at the inner half of the anterior chamber was a yellowish white vascular tumour with haemorrhages on its summit. The part of iris free from tumour was slightly discoloured and there was pericorneal injection. Microscopical examination showed that the iris tissue was much atrophied on the affected side and in many places only the pigment layers were recognizable. The iris was to a large extent pierced by the tumour which extended on to both the anterior and posterior surfaces of the iris, so that iris tissue and the pigment layers were enclosed by carcinomatous tissue.

Chiarini ${ }^{25}$ recorded the case of a male, aged 54, with lung carcinoma in which there were two small nodules on the lower part of the left iris, and later another similar nodule on the iris of the right eye. Microscopical examination showed that the swelling on the iris of each eye consisted of epithelial cells. The ciliary bodies were normal, but the choroid in each eye was infiltrated with similar epithelial cells.

Proctor and Verhoeff's ${ }^{26}$ case of metastatic carcinoma of the iris. A woman, aged 72, had a breast removed for carcinoma in 1903. 
She was seen on account of her eye in June, 1905, when an irregular oval spot above the pupil a little nearer to pupillary border than ciliary region was present. It was $3 \mathrm{~mm}$. in length and $2 \mathrm{~mm}$. wide and projected slightly beyond the plane of the iris. On the anterior surface were several coral-like excrescences. The tumour was greyish brown, considerably lighter than the surrounding dark brown iris; projections on the anterior surface were greyishwhite; no inflammatory symptoms; fundus normal. The tumour of iris was removed by iridectomy and examined microscopically. The tumour was growing entirely within the stroma of iris, had no capsule, and was not sharply marked off from the normal tissue. The tumour cells were closely packed together. All that remained of the iris stroma were blood-vessels and a few strands of connective tissue. The pigment epithelium was intact. Mitotic figures were abundant. The tumour cells were large with cytoplasm almost transparent, diffusely staining nuclei, and nucleoli well preserved. Occasionally cells were grouped about a lumen or lined a tissue space. The exact nature of the tumour was less easy to recognise from the histological examination. The patient died in September 1905.

Toulant' ${ }^{27}$ case was that of a female, aged 31 , with primary breast cancer. There were nodules on both irides. In the left eye the iris shews; (1) a nodule on its free border, in the upper-outer quadrant. This swelling is of the same colour as the rest of the iris, and is 2 to $3 \mathrm{~mm}$. in diameter. It does not appear to be adherent to the lens-the pupillary reflexes (to light and on convergence) are present. (2) Along the attached border of the iris, at the upper part of the upper-outer quadrant are two tiny swellings of a reddish white colour. The rest of the iris appears normal. Right eye : In the upper-inner quadrant is seen a small yellowish neoplasm situated in the corneo-iridic angle. It measures less than $2 \mathrm{~mm}$. in length, is about $1 \mathrm{~mm}$. broad, and appears to be composed of several small nodules massed together. The media and fundus were normal in each eye, Cutaneous nodules and some hypertrophied glands were noticed by the patient at the same time as the first eye symptoms. Unfortunately a description of the microscopical appearances of the iris is wanting in this case.

There are some other cases where on microscopical examination cancer cells were found in the iris, but, in which there is no clinical evidence of the tumour or else no description of it is given $\left(\right.$ Brewitt $^{28}$, Ishihara ${ }^{29}$, v. Hippel ${ }^{30}$ ). In Abelsdorff' ${ }^{31}$ case of metastatic carcinoma of both choroids the eyes appeared to be normal on external examination, yet there was an infiltration of cancer cells at the root of each iris. Chance's $\mathrm{s}^{32}$ case of secondary hypernephroma of the iris and ciliary body has purposely not been included here with the cases of metastatic carcinoma of the iris. An iridectomy 
was done in the left eye of a man for a supposed sarcoma of iris. From microscopical examination of the sections perithelial sarcoma was diagnosed. Subcutaneous nodules were excised and pronounced by a second observer to be sarcomata. The left eye was excised later on and the ciliary neoplasm was regarded as a small round celled sarcoma by a third observer. Professor Allen J. Smith who at first had supposed the iris tumour to be a perithelial sarcoma, believed that the tumour was an endothelioma when he had compared the sections with those of the subcutaneous nodules, but a few days later he made the diagnosis of hypernephroma. Subsequently at the autopsy a hypernephroma of the left kidney was found.

The seven cases of metastatic carcinoma of iris which presented clinical appearances and were subsequently examined microscopically occurred in five females with mammary cancer and in two males, one with cancer of the lung and the other with stomach cancer. The ages of the cases ranged from 32 to 72 . These cases show that a metastatic carcinoma of the iris appears as a small shallow swelling of the iris, as a nodule of circular or oval shape, and sometimes as a slightly raised mass. The swellings are sharply, or fairly sharply, defined. Their colour is variable and has been described as reddish, dull grey, greyish red, and greyish brown. Usually only one iris is involved. The tumour is most frequently single, but may be multiple. These tumours are found on any part of the iris-the pupillary area, the root, and the intermediate area. They occur at the upper part of the iris, the lower part, the outer part, and at the lower inner part. Some of them are obviously vascular. The iris may retain its normal appearance except at the site of the tumour, and the pupil may contract to light. Microscopically the carcinoma is found to arise in the iris stroma, which becomes infiltrated with epithelial cells; it has no capsule. On comparing case $\mathrm{C}$. with these seven cases there is much in common, there is the raised fairly well defined swelling of iris; with the rest of the iris retaining its normal appearance, and the pupil active to light, only one iris affected and the growth a single one. It differs from these cases in its dark colour and its red appearance on transillumination. Its cystic appearance as seen clinically and in sections is not found in the other cases or in the cases recorded by Abelsdorff, Brewitt, Ishihara, and v. Hippel, so in this respect it appears to be unique.

If we believe that these iris carcinomata originate from emboli derived from a tumour in some other part of the body then the cancer cells must be conveyed either by the anterior ciliary arteries or by the long posterior ciliary arteries. Any doubt as regards the embolic origin of these iris tumours might be increased, first, by 
the fact that in four of these eight cases (case C. included) a carcinoma was present in the choroid as well as in the iris, and, secondly, by the report of a normal fundus in one of the four remaining cases being based entirely on clinical observation. It might be supposed that the carcinoma cells came from the choroidal growths and that they were conveyed in some manner, perhaps by dissemination, ${ }^{*}$ to the iris where they developed. Against any such view is the early presence of the iris tumour in case C., almost certainly before there was any tumour in the choroid. Further, in the case just referred to it is unlikely that a choroidal tumour, had such been present, would not have shown some clinical evidence of its presence.

The five metastatic choroidal carcinomata observed clinically in cases A. and C. emphasize the importance of the following points in forming a diagnosis of these tumours. $\Lambda$ swelling arises at the posterior part of the fundus in the region of the posterior ciliary arteries. It has a pale grey colour, and the margin is not sharply defined; it increases rapidly. In addition to these points all of the tumours showed a grey mottling which was quite evident, but not conspicuous, and was most marked at the edge of the swelling. As showing the similarity of the tumours in the two cases, the fundus appearance in the left eye of case $\mathrm{C}$. at the first examination at once recalled that of the choroidal carcinoma that had been seen in case A. more than two years previously. Should both eyes become affected, or multiple swellings appear in one eye, then a diagnosis of metastatic carcinoma would be strengthened. Minute black pigment spots may, or may not, be present on the swelling.

From a survey of the literature of choroidal carcinoma it is seen that both eyes were affected in about a third of the cases-30 in 98 cases. In 68 cases one eye only was affected-the right eye 34 times and the left eye 34 times. The sex is mentioned in 102 of the cases. There are 73 females and 29 males. Extra-ocular growths with destruction of the sclerotic are unusual, for the patient generally succumbs before this occurs.

Carcinomatous growth passing from the optic disc in finger-like processes into the optic nerve, as occurred in case B., is also of rare occurrence. The commonest age for carcinoma of the choroid to occur is from the fortieth to the forty-ninth year, and the period of life next in order of frequency is from fifty to fifty-nine years of age, and then the period from thirty to thirty-nine years. The oldest was 72 years and the youngest 20 years.

\footnotetext{
*See paper by v. Michel, IX Congrès Périodique International d'Ophtalmologie.
} 
Table to show the number of cases that occurred during different periods of life.

$\begin{array}{ccccccccc}\text { AGE } & & & & & & & & \\ 20-29 & \ldots & \ldots & \ldots & \ldots & \ldots & \ldots & \ldots & 4 \\ 30-39 & \ldots & \ldots & \ldots & \ldots & \ldots & \ldots & \ldots & 18 \\ 40-49 & \ldots & \ldots & \ldots & \ldots & \ldots & \ldots & \ldots & 36 \\ 50-59 & \ldots & \ldots & \ldots & \ldots & \ldots & \ldots & \ldots & 25 \\ 60-69 & \ldots & \ldots & \ldots & \ldots & \ldots & \ldots & \ldots & 10 \\ 70-79 & \ldots & \ldots & \ldots & \ldots & \ldots & \ldots & \ldots & 1\end{array}$

In the remaining sixteen cases there is no mention made of the age. The tension of the eyeball may be normal, increased, and, in a few cases, diminished. Of the 75 eyes with a record of tension, 38 had normal tension, 31 had increased tension, and 6 showed diminished tension.

The average duration of life after the eye is affected is nearly eight months- 7.87 months. The longest time recorded is two years, and the shortest time one month.

The primary growth occurred most frequently in the mammary gland and then in the lungs. The stomach, thyroid, liver and rectum come next in order of frequency, and finally a single case is recorded for each of the following organs, oesophagus, suprarenal body, prostate and ovary. In females the mamma is by, far the commonest situation for the primary growth; in males the lung is the most frequent site.

Table to show relative frequency of the primary growth in various parts of the body in males and females :-

\begin{tabular}{|c|c|c|c|c|c|c|c|c|c|c|}
\hline & Mamma & Lungs & Stomach & Thyroid & Liver & Rectum & $\begin{array}{c}\text { Oesoph } \\
\text { agus }\end{array}$ & $\begin{array}{l}\text { Supra. } \\
\text { renal } \\
\text { body }\end{array}$ & $\begin{array}{c}\text { Pros- } \\
\text { tate }\end{array}$ & Ovary \\
\hline Males ...19 & 3 & 6 & 2 & 1 & 2 & 2 & 1 & 1 & 1 & - \\
\hline Females...71 & 62 & 4 & 1 & 2 & 1 & - & - & - & $1-$ & 1 \\
\hline Total $\quad \ldots 90$ & 65 & 10 & 3 & 3 & 3 & 2 & 1 & 1 & 1 & 1 \\
\hline
\end{tabular}

The carcinomatous tumour in the iris stroma of case C. obviously preceded by a considerable interval the deposit of cancer cells in the choroid. Its growth was slow, thus differing from similar growths in the choroid.

My thanks are due to Sir John Herbert Parsons for his opinion regarding the eye sections of cases $\mathrm{A}$. and $\mathrm{C}$. which agrees with the conclusions expressed in the paper, to Professor A. W. Mackintosh for his notes of cases A. and C., and to Professor Shennan for his report on the post mortem examination of case C. I am also indebted to Dr. Alexander Low for the excellent micro-photographs, and to Dr. H. Edgar Smith for his early records of case C. and the preparation of the sections from cases $\mathrm{A}$. and $\mathrm{C}$. 


\begin{tabular}{|c|c|c|c|c|c|c|}
\hline 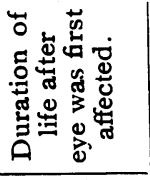 & 1 & 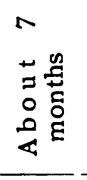 & 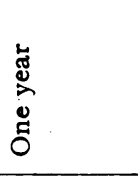 & 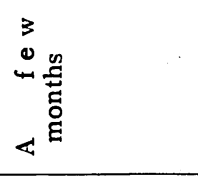 & 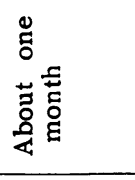 & 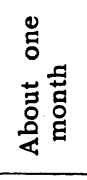 \\
\hline 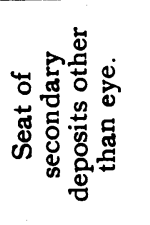 & 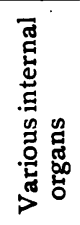 & 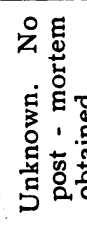 & 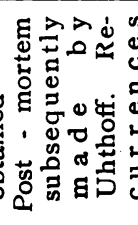 & 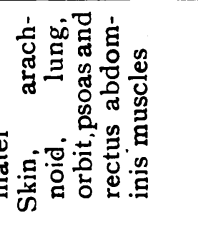 & 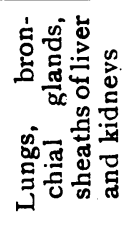 & 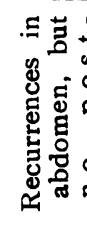 \\
\hline 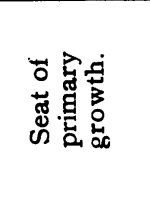 & 望 & 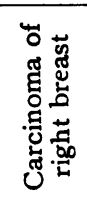 & 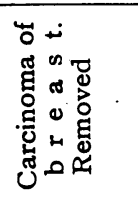 & $\stackrel{\stackrel{ٌ}{3}}{3}$ & 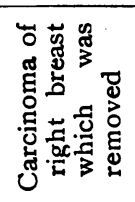 & 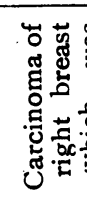 \\
\hline 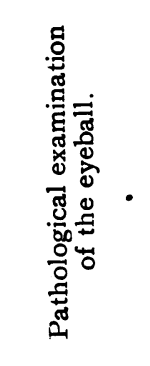 & 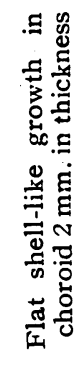 & 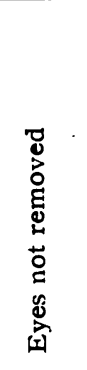 & 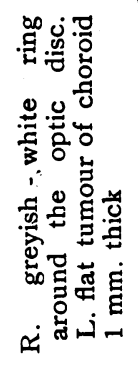 & 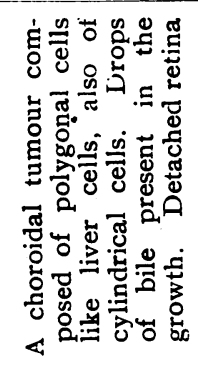 & 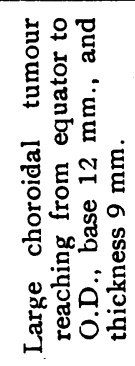 & 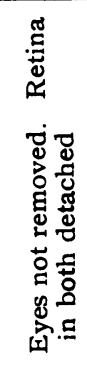 \\
\hline 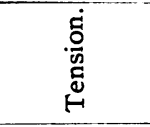 & 1 & 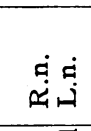 & $\begin{array}{l}\dot{+}+\dot{\leftrightarrow} \\
\dot{\leftrightarrow} \\
\dot{\alpha}\end{array}$ & $\stackrel{+}{+}$ & $\vec{H}$ & 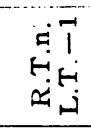 \\
\hline ندة & $x \bar{x}$ & 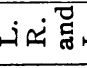 & 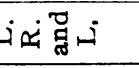 & i & i & 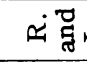 \\
\hline $\begin{array}{l}\dot{5} \\
\dot{8} \\
\dot{a}\end{array}$ & $q$ & N & $m$ & g & $\stackrel{\infty}{N}$ & in \\
\hline 离 & $\dot{\Sigma}$ & मі & 的 & $\dot{\Sigma}$ & 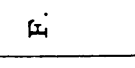 & 庄 \\
\hline 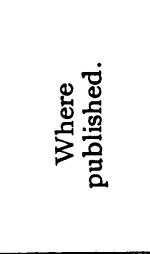 & 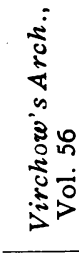 & 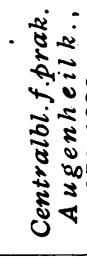 & 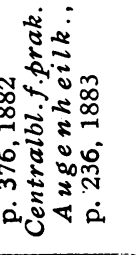 & 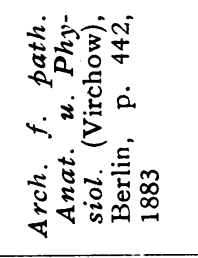 & 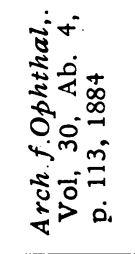 & 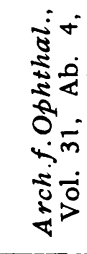 \\
\hline $\begin{array}{l}\text { 岁 } \\
\text { 妾 }\end{array}$ & $\begin{array}{c}\vdots \\
\vdots \\
\frac{n}{b} \\
n_{1}^{\infty}\end{array}$ & 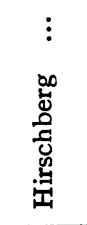 & 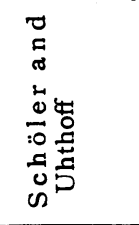 & 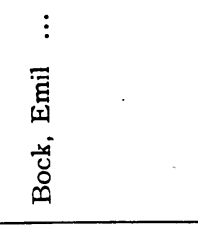 & 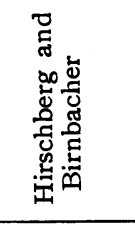 & $\begin{array}{l}\vdots \\
\vdots \\
N \\
\tilde{N} \\
\sum\end{array}$ \\
\hline $\begin{array}{l}\dot{0} \\
\dot{y} \\
\dot{z}\end{array}$ & $r$ & N & $m$ & + & in. & 0 \\
\hline
\end{tabular}


Metastatic Carcinoma of the Choroid and Iris 41

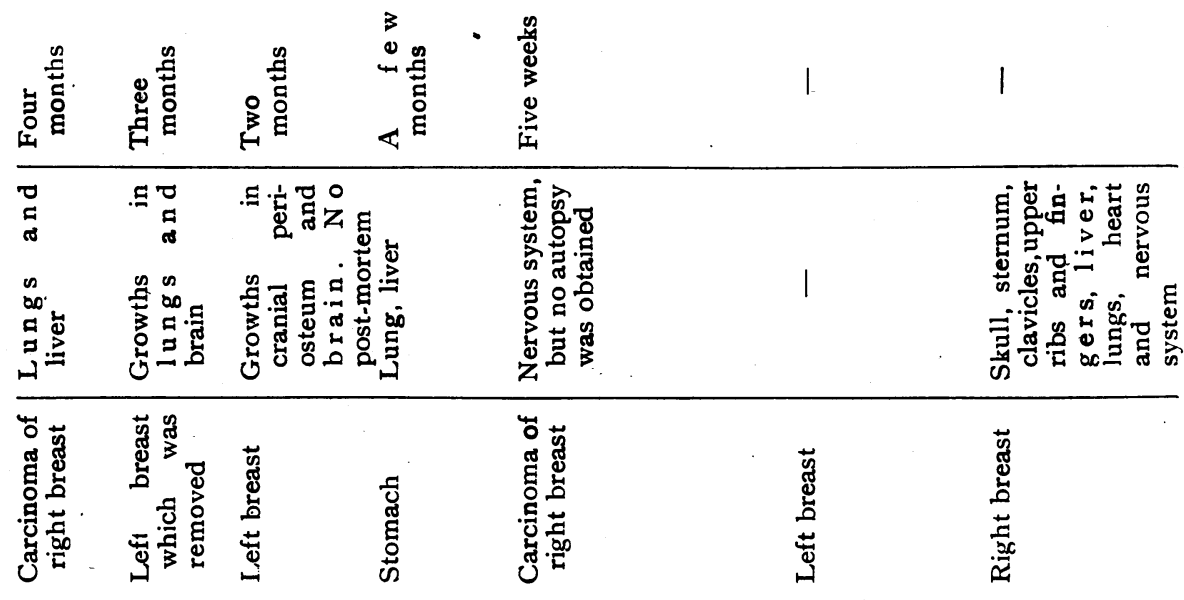

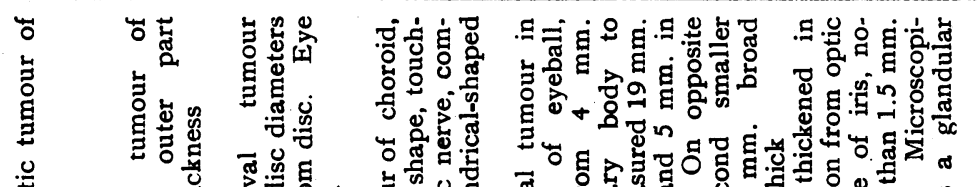

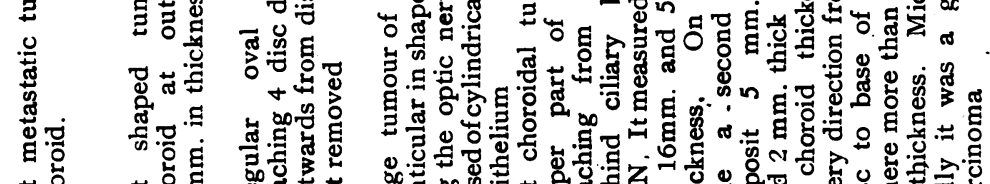

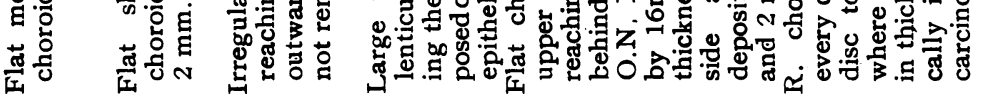

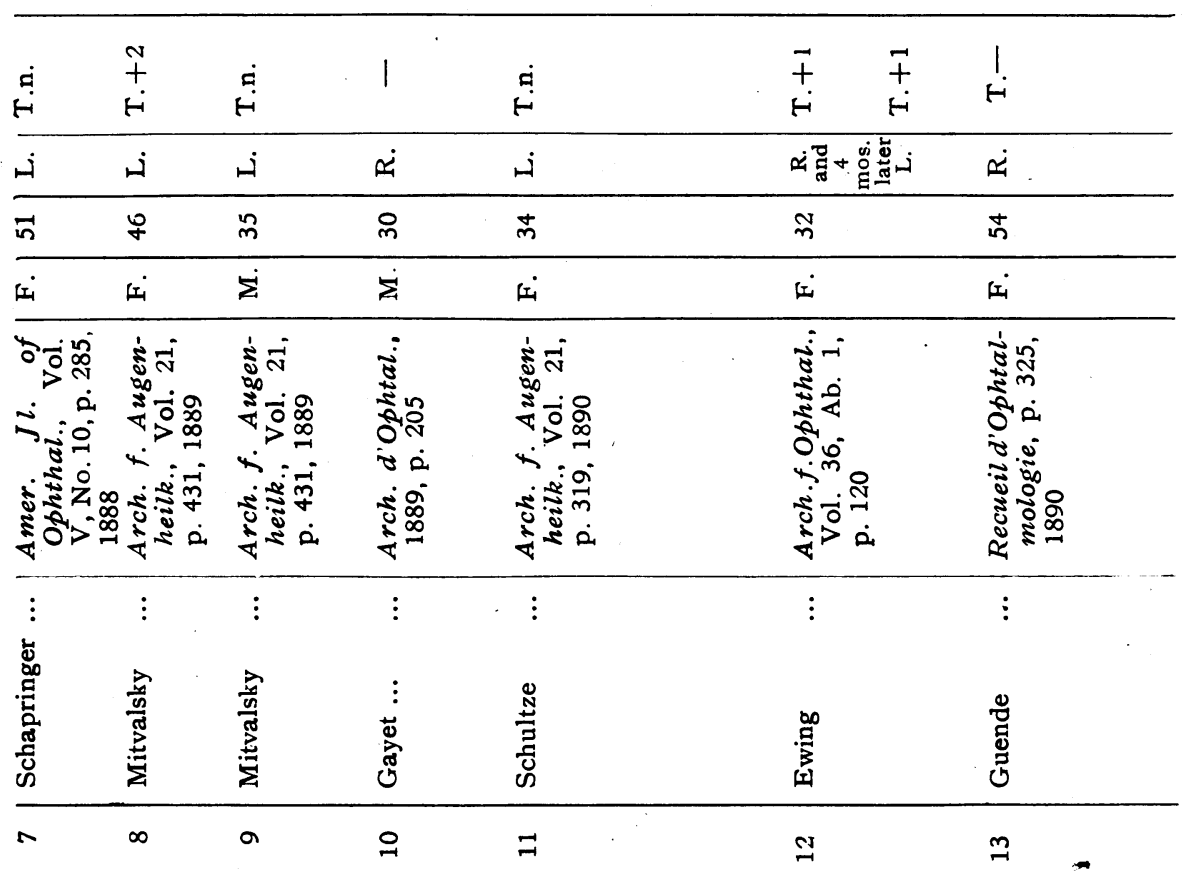




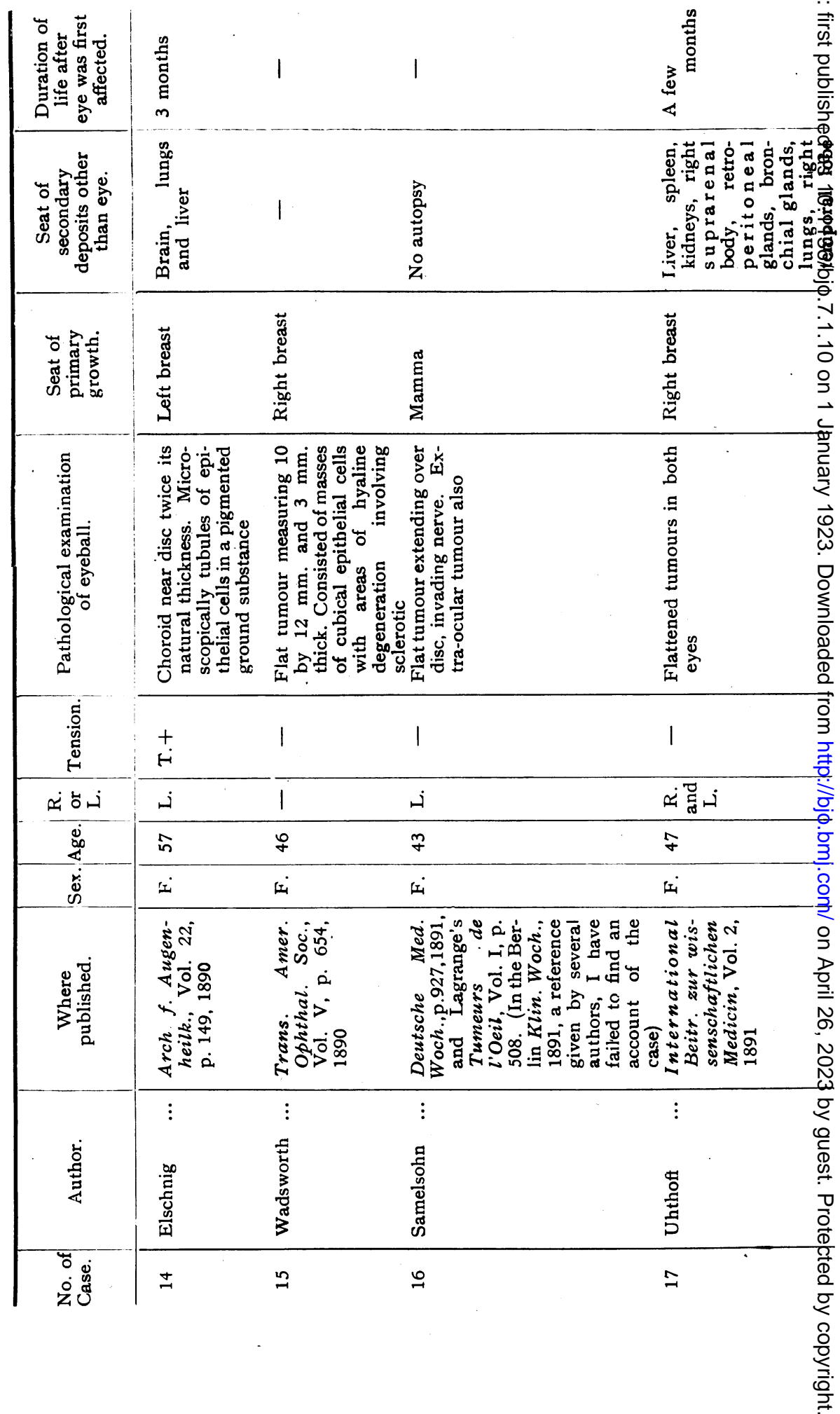



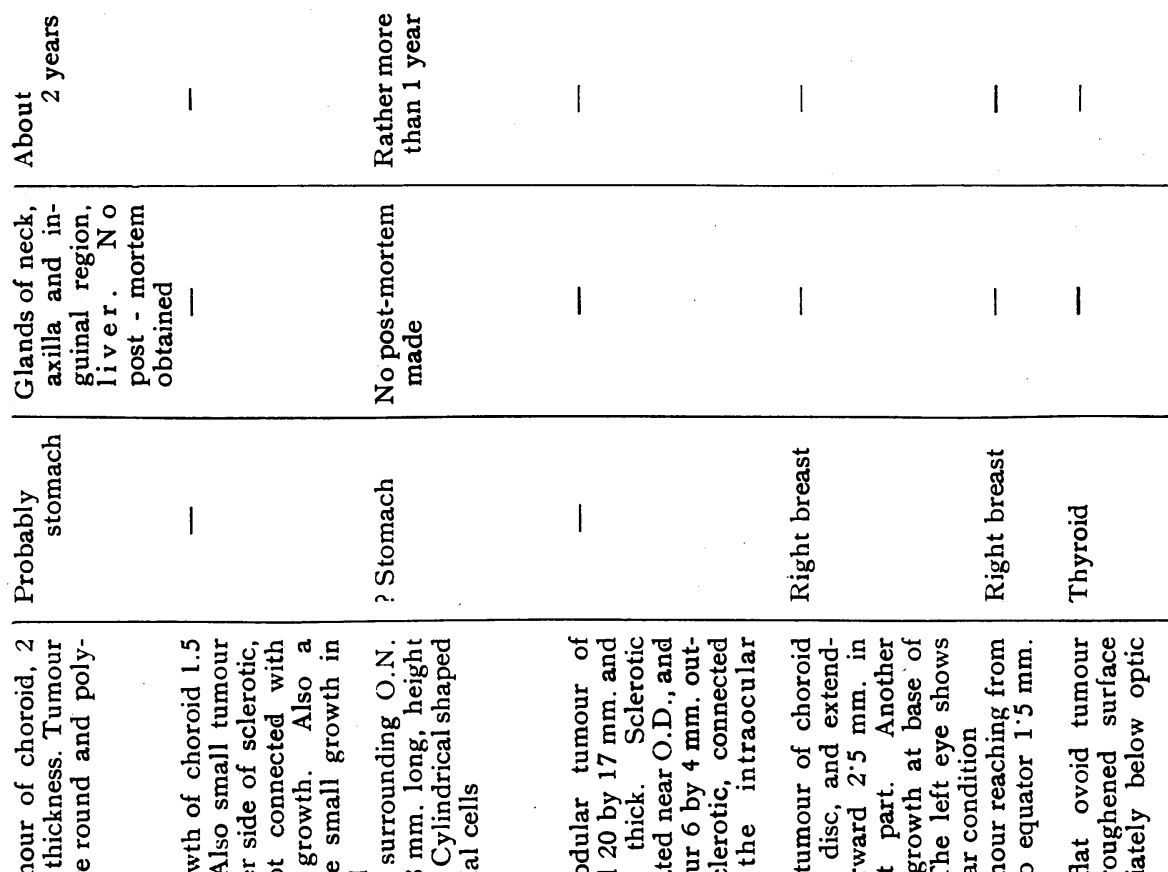

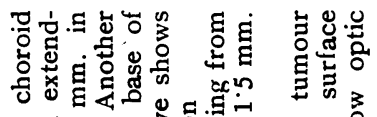

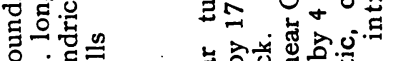
岁苋

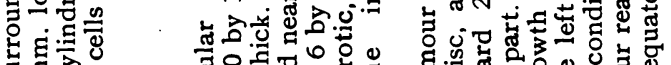

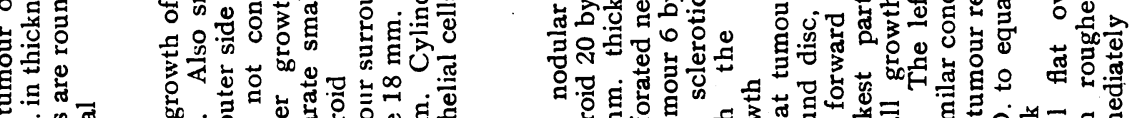

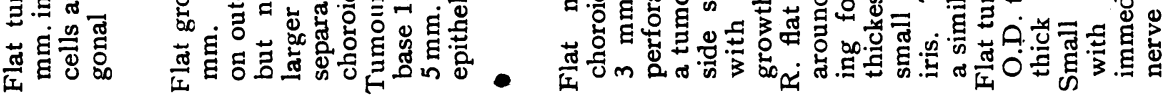

\begin{tabular}{|c|c|c|c|c|c|c|}
\hline $\begin{array}{l}+ \\
H\end{array}$ & 1 & $\underset{H}{+}$ & 1 & $\underset{H}{\dot{H}}$ & 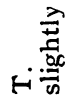 & \\
\hline$j$ & 1 & ن & $\stackrel{-}{-}$ & ن & نهم & $\approx$ \\
\hline$\xi$ & 1 & $\hat{m}$ & mे & 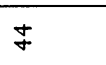 & in & 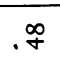 \\
\hline$\dot{\Sigma}$ & 1 & $\Sigma$ & ⿷匚 & 庄 & Ii & 4. \\
\hline
\end{tabular}

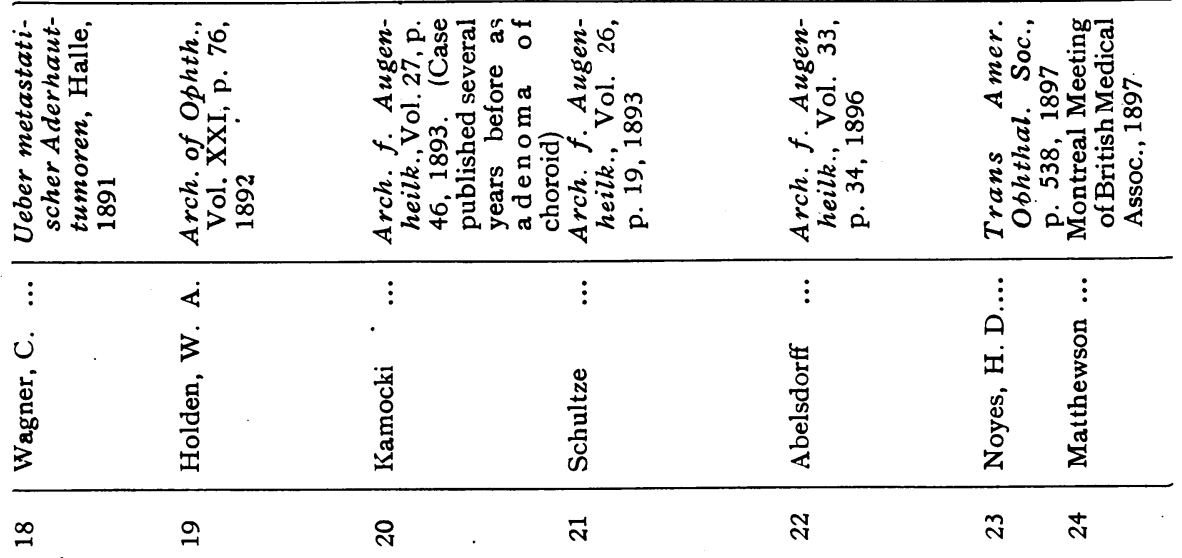


The British Journal of Ophthalmology

\begin{tabular}{|c|c|c|c|c|c|c|c|c|c|c|}
\hline 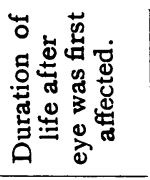 & 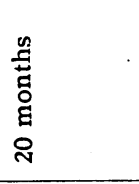 & 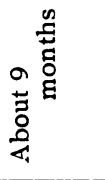 & 1 & 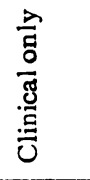 & 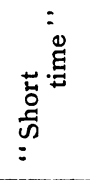 & 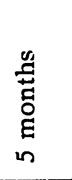 & 1 & 1 & 1 & $1 \frac{\stackrel{0}{0}}{\frac{0}{0}}$ \\
\hline 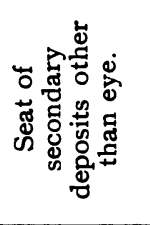 & 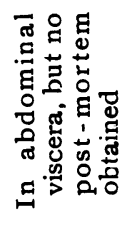 & 1 & 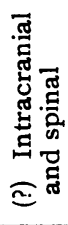 & 1 & 1 & 1 & 1 & 1 & 1 & 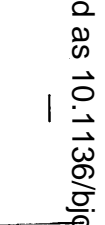 \\
\hline 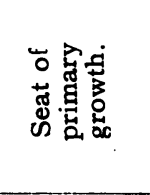 & 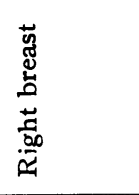 & 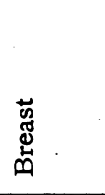 & 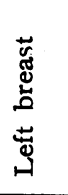 & 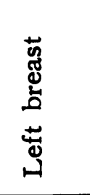 & 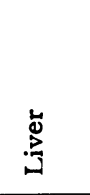 & 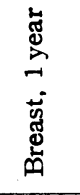 & 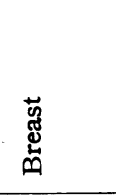 & 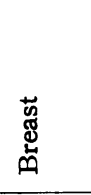 & 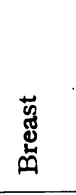 & 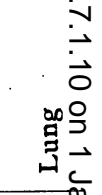 \\
\hline 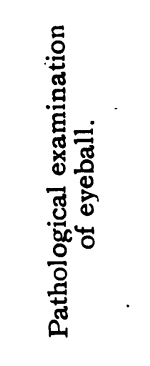 & 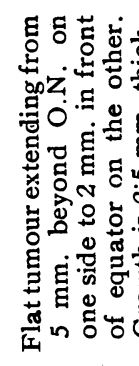 & & 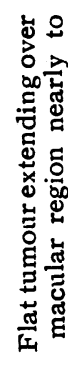 & 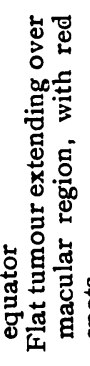 & 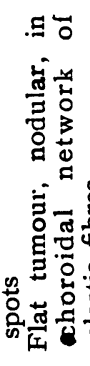 & 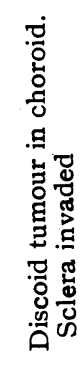 & 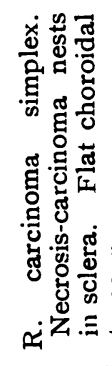 & 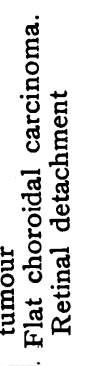 & 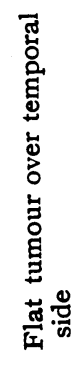 & 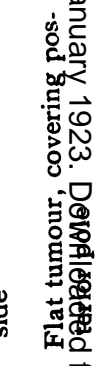 \\
\hline 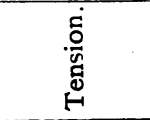 & $\stackrel{\dot{B}}{H}$ & 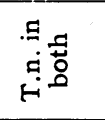 & $\stackrel{\dot{4}}{H}$ & 1 & 1 & 1 & $\underset{H}{\dot{4}}$ & $\underset{H}{+}$ & $\stackrel{\dot{\leftrightarrow}}{\circ}$ & \\
\hline هُ & $\dot{x}$ & نَّ & $\dot{\alpha}$ & نـ & نهم & \multicolumn{2}{|c|}{ نَّة } & $\dot{H}$ & 1 & $-\frac{1}{2}$ \\
\hline 宛. & in & Z & \& & p & $\stackrel{\infty}{n}$ & q & $\xi$ & \& & 1 & \\
\hline 㤐 & si & 应 & 4 & Li & ⿷匚 & 幽 & Li & Li & 庄 & 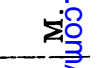 \\
\hline 焉 & 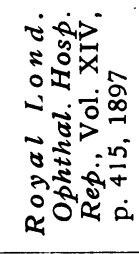 & 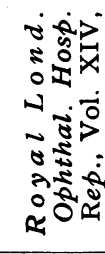 & & & 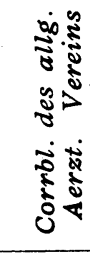 & $\left\{\begin{array}{l}\bar{m} \\
\dot{n} \\
\dot{n}\end{array}\right.$ & 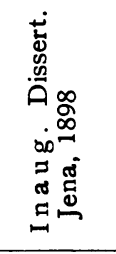 & 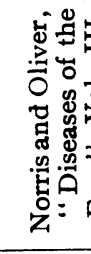 & 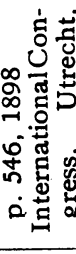 & 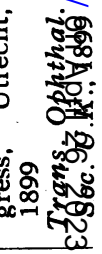 \\
\hline 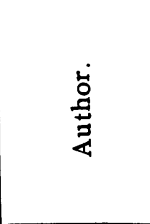 & 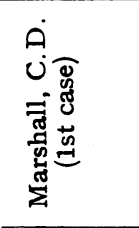 & 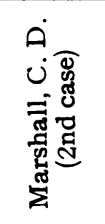 & 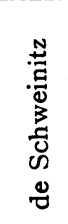 & 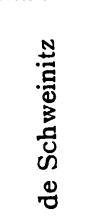 & 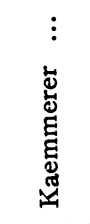 & 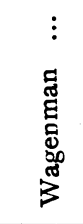 & 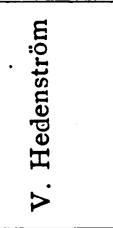 & $\begin{array}{l}\vdots \\
= \\
= \\
: 0 \\
0.0 \\
\text { in }\end{array}$ & 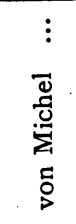 & 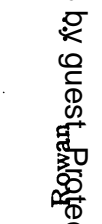 \\
\hline 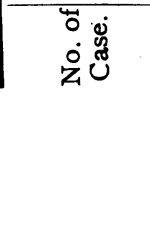 & \& & $\stackrel{\text { s }}{2}$ & N & $\stackrel{\infty}{N}$ & शे & 요 & $\vec{m}$ & $\tilde{m}$ & $m$ & 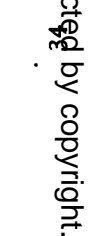 \\
\hline
\end{tabular}



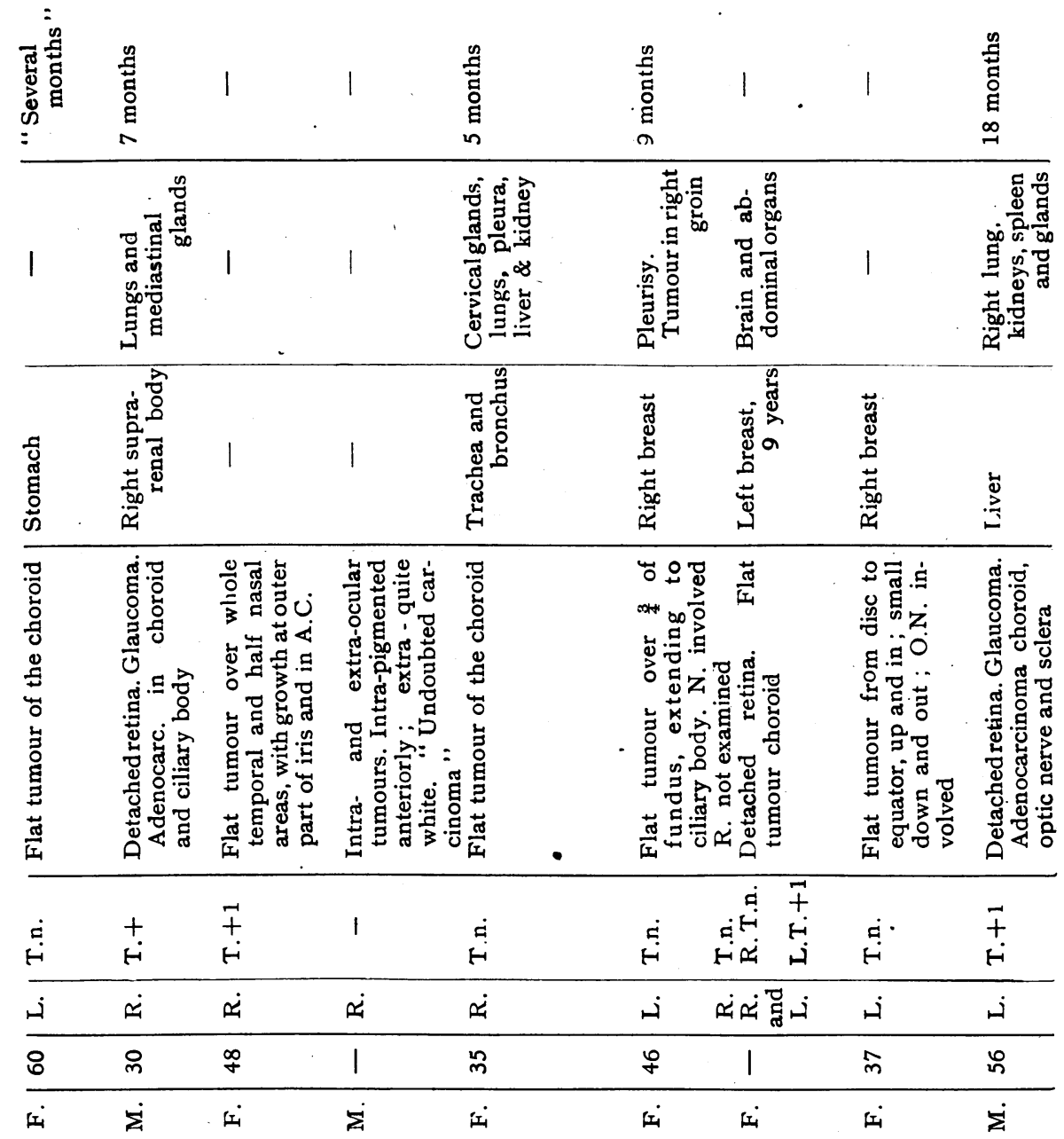

\begin{tabular}{|c|c|c|c|c|c|c|}
\hline 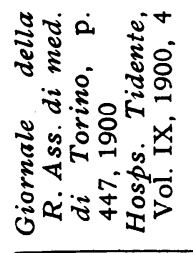 & 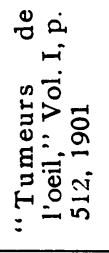 & $\stackrel{\stackrel{*}{*}}{\vec{\theta}}$ & 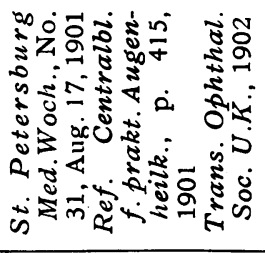 & 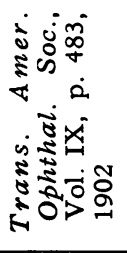 & 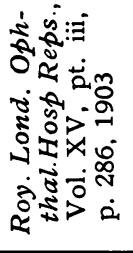 & $\begin{array}{l}8 \\
0 \\
0\end{array}$ \\
\hline
\end{tabular}

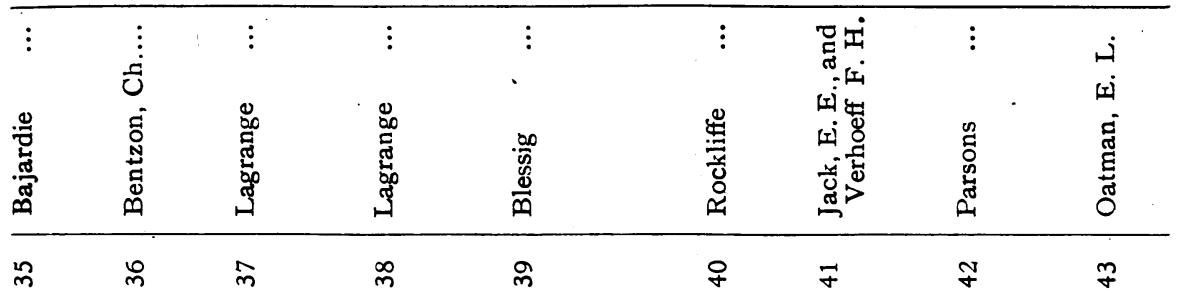




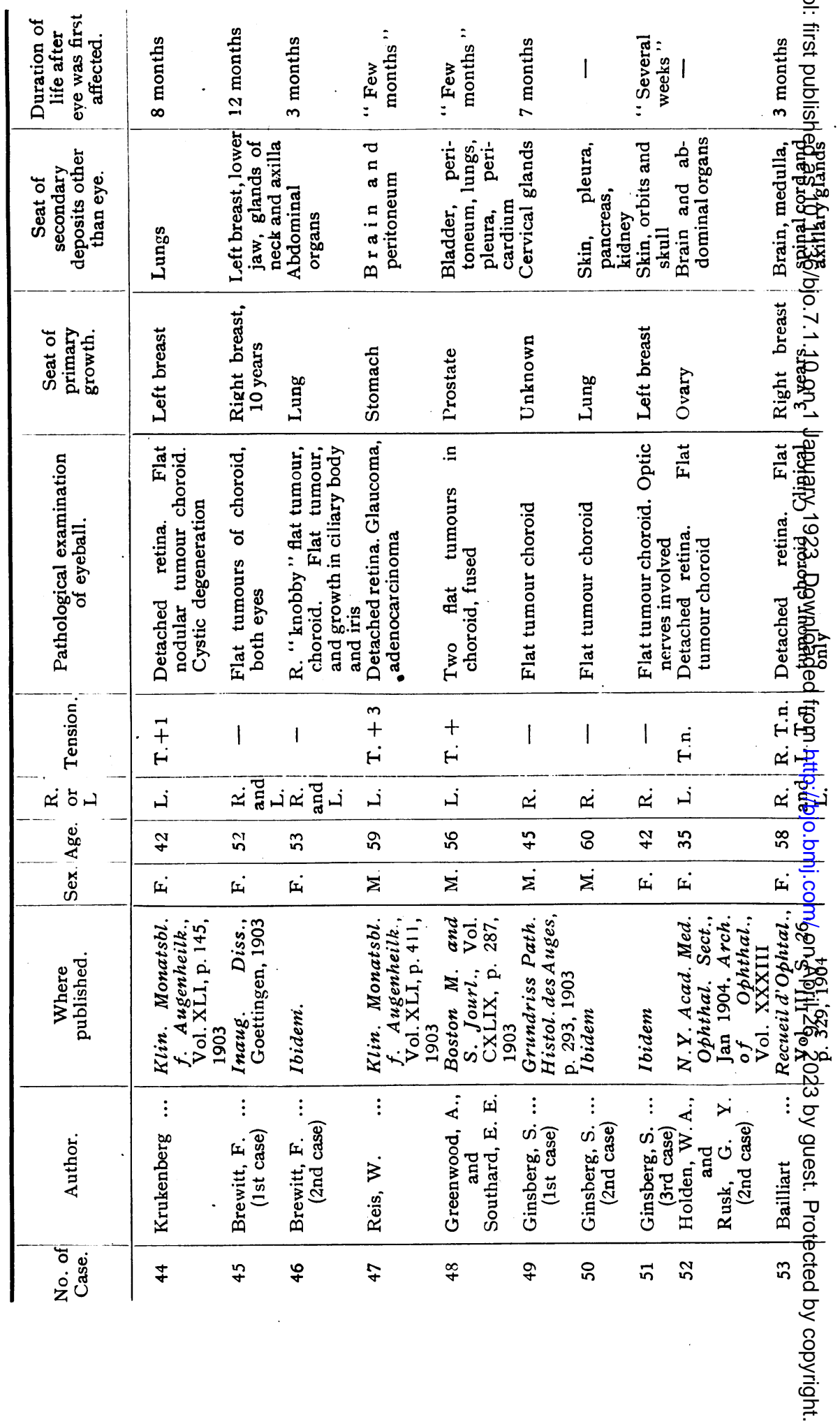


Metastatic Carcinoma of the Choroid and Iris $4 \boldsymbol{\tau}$

\begin{tabular}{|c|c|c|c|c|c|c|c|c|}
\hline 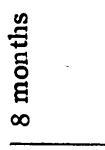 & 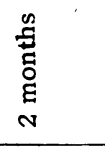 & 1 & 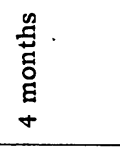 & 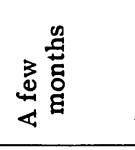 & 1 & $\begin{array}{l}n \\
\stackrel{n}{E} \\
\tilde{E} \\
\Xi \\
\infty \\
\end{array}$ & 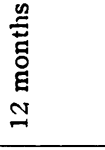 & 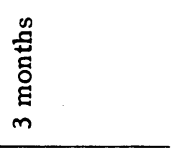 \\
\hline 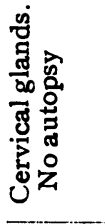 & 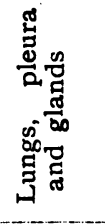 & 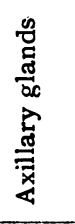 & 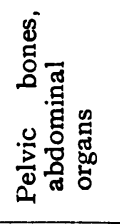 & 1 & 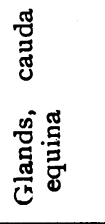 & 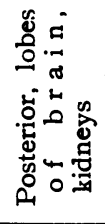 & 1 & 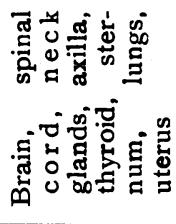 \\
\hline 1 & 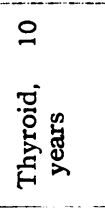 & $\stackrel{\text { 品 }}{\stackrel{5}{\Xi}}$ & 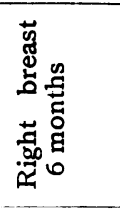 & 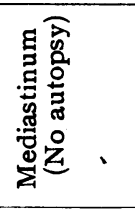 & 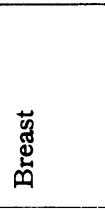 & 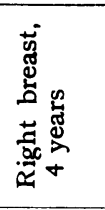 & 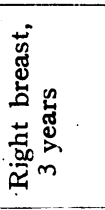 & 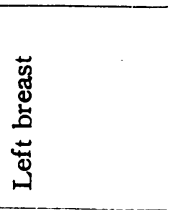 \\
\hline 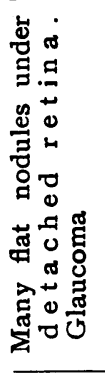 & 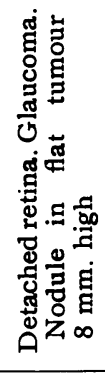 & 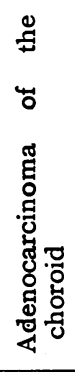 & 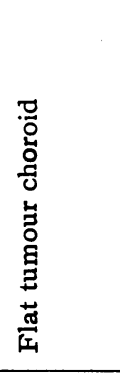 & 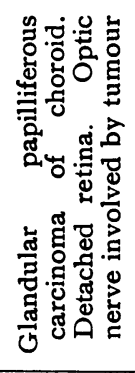 & 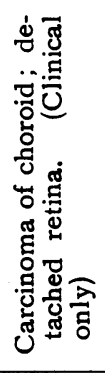 & 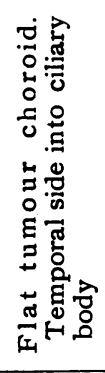 & 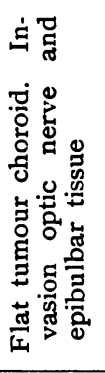 & 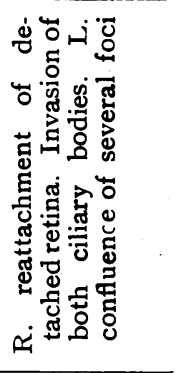 \\
\hline 1 & $\begin{array}{l}m \\
+ \\
+\end{array}$ & 1 & 1 & $\stackrel{\dot{\leftrightarrow}}{\dot{H}}$ & 1 & $\stackrel{+}{+}$ & $\stackrel{+}{\dot{H}}$ & 1 \\
\hline 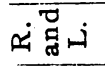 & $\dot{1}$ & 1 & 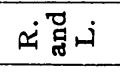 & $\dot{\sim}$ & $\dot{0}$ & $\simeq$ & $\dot{x}$ & ن \\
\hline q & in & 1 & q & F & 8 & $\stackrel{\infty}{+}$ & $\stackrel{\infty}{+}$ & th \\
\hline$\dot{\Sigma}$ & 压 & 届 & $\dot{4}$ & $\dot{\Sigma}$ & $\dot{\Sigma}$ & 㝳 & 庄 & \&i \\
\hline
\end{tabular}

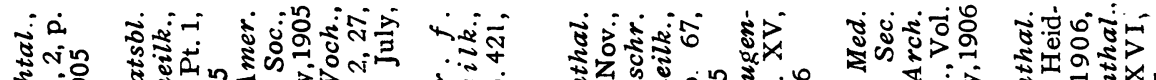

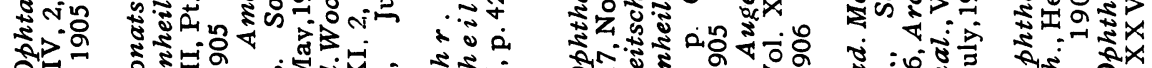
ơ

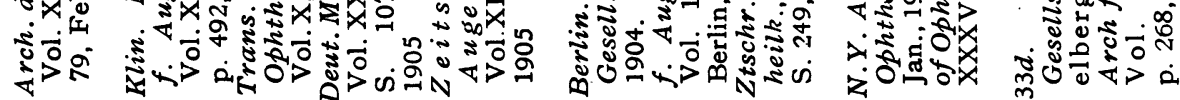




\begin{tabular}{|c|c|c|c|c|c|c|}
\hline 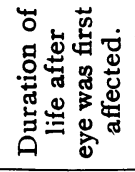 & 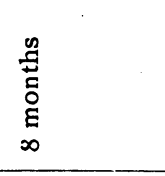 & 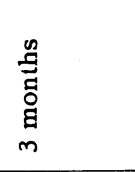 & 1 & 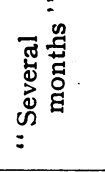 & 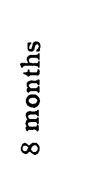 & 1 \\
\hline 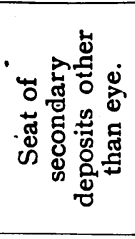 & 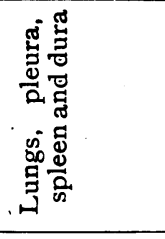 & 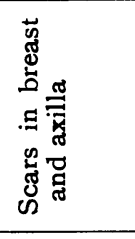 & 1 & 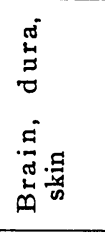 & 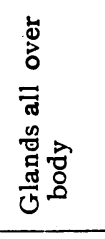 & 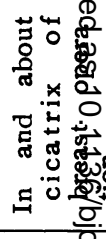 \\
\hline 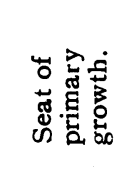 & 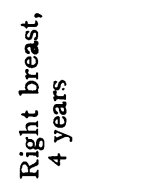 & 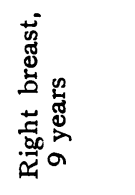 & $\stackrel{\infty}{\Xi}$ & 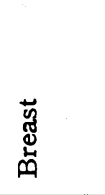 & 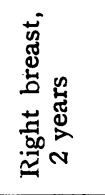 & 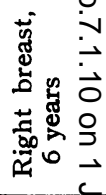 \\
\hline 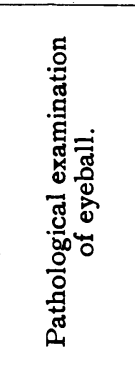 & 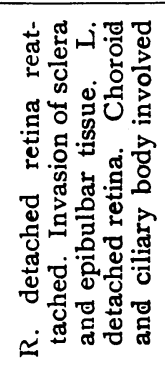 & 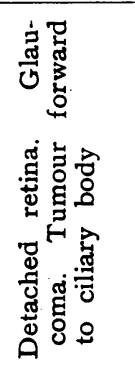 & 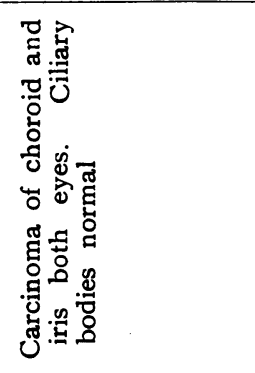 & 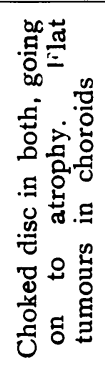 & 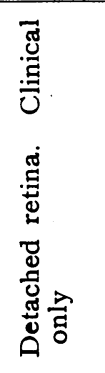 & 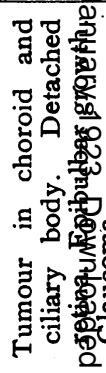 \\
\hline 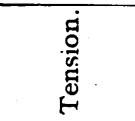 & 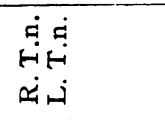 & $\stackrel{+}{+}$ & 11 & 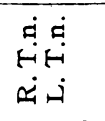 & 1 & $\begin{array}{r}+3 \\
+ \\
\dot{H}\end{array}$ \\
\hline 地 & $\therefore$ 菏亡 & $\dot{\alpha}$ & ن & ن & ن & $\dot{H}$ \\
\hline 离 & $\hat{f}$ & $\vec{m}$ & 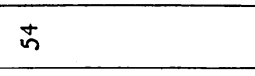 & in & $\stackrel{m}{m}$ & $\vec{b}$ \\
\hline $\begin{array}{c}\stackrel{\dot{x}}{0} \\
\omega\end{array}$ & 庄 & 度 & $\dot{\Sigma}$ & A & $i$ & 4 \\
\hline 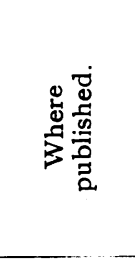 & 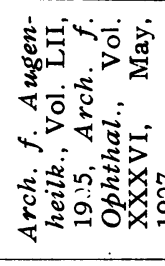 & 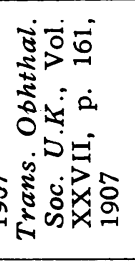 & 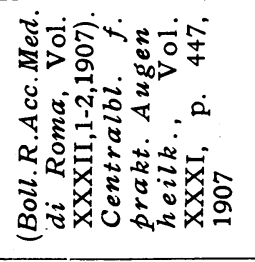 & 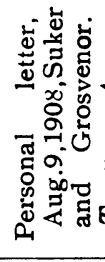 & 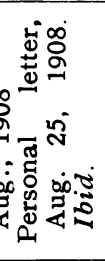 & 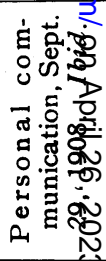 \\
\hline 旁 & $\dot{\vdots}$ & 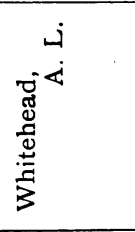 & 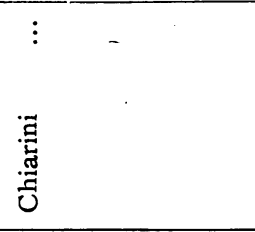 & 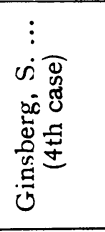 & $\begin{array}{l}\dot{x} \\
\dot{H} \\
\dot{0} \\
\dot{0} \\
\dot{0} \\
\dot{0}\end{array}$ & 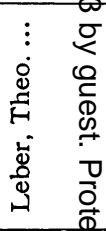 \\
\hline 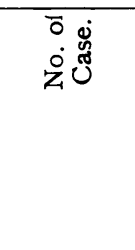 & $\ddot{0}$ & t & ถి & 8 & $\hat{0}$ & $\begin{array}{lll}\infty & \mathbb{0} \\
\stackrel{0}{0}\end{array}$ \\
\hline
\end{tabular}




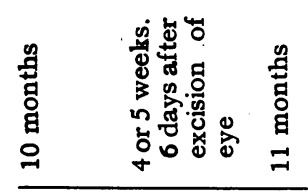

\begin{tabular}{|c|c|c|c|c|c|c|c|c|}
\hline 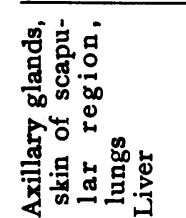 & 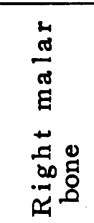 & 1 & & 1 & 1 & 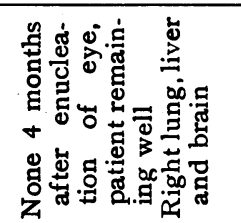 & 1 & \\
\hline
\end{tabular}

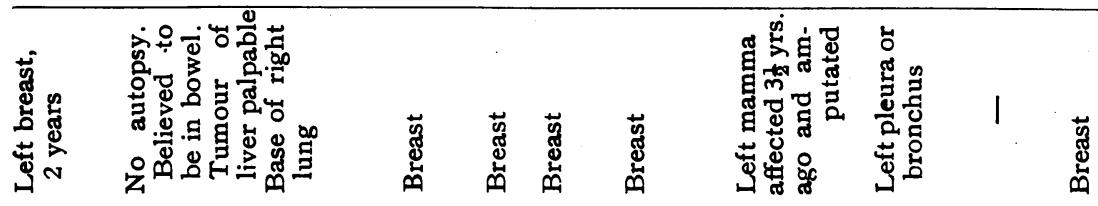

\begin{tabular}{|c|c|c|c|c|c|c|c|c|}
\hline 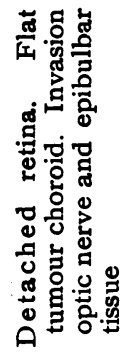 & 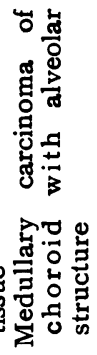 & 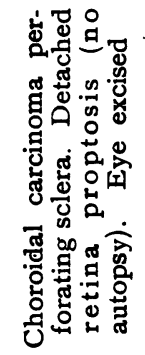 & 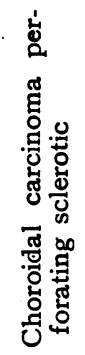 & 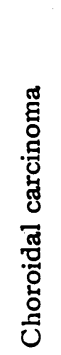 & 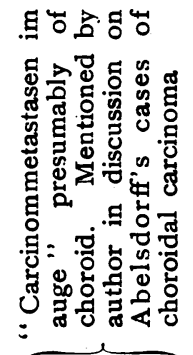 & 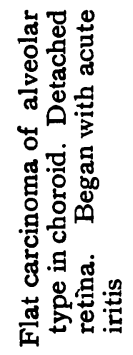 & 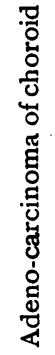 & 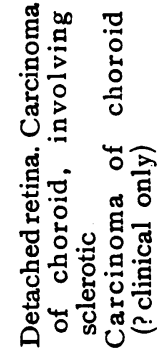 \\
\hline
\end{tabular}

F

\begin{tabular}{|c|c|c|c|c|c|c|c|c|c|}
\hline 8 & $\mathcal{F}$ & 1 & 1 & 1 & 1 & 1 & $F$ & $\ddot{6}$ & 1 \\
\hline$\Sigma$ & $\dot{\Sigma}$ & II & 虍 & 1 & 1 & I & $\sum_{i}$ & 1 & 1 \\
\hline
\end{tabular}

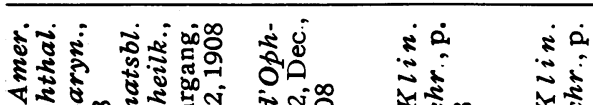

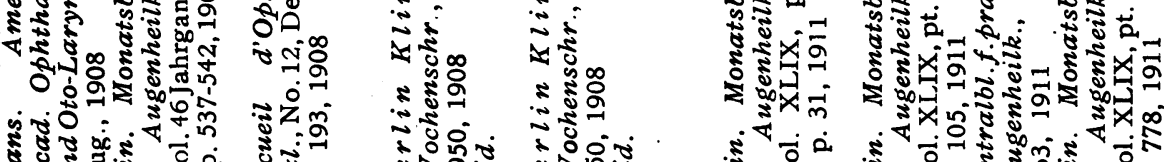

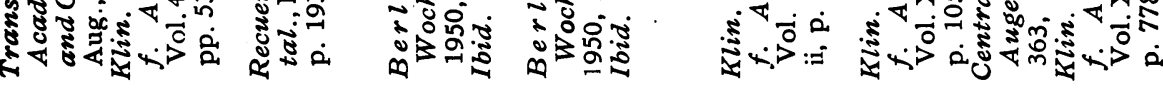




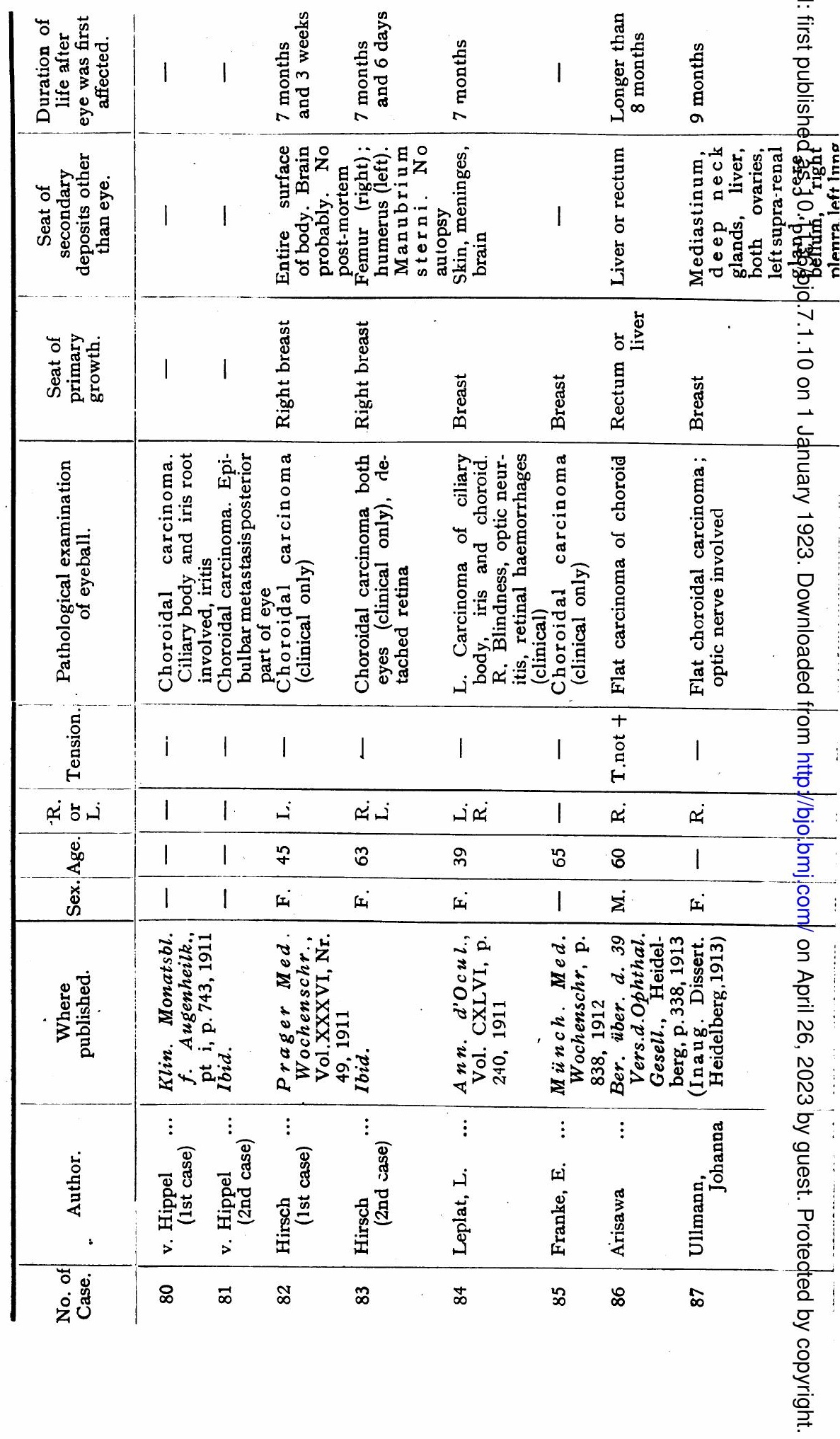


Metastatic Carciñoma of the Choroid and Iris 51

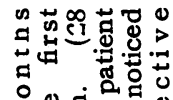

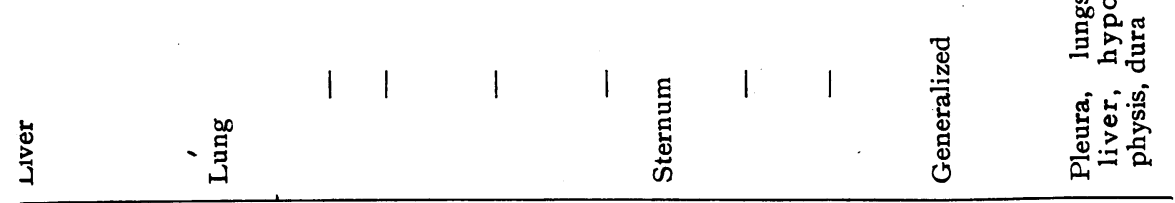

\begin{tabular}{|c|c|c|c|c|c|c|c|c|c|}
\hline 龍. & 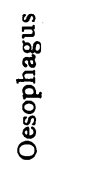 & 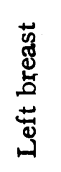 & $\begin{array}{l}\text { 菋 } \\
\text { m }\end{array}$ & 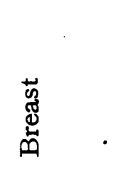 & 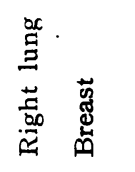 & 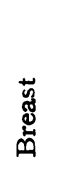 & 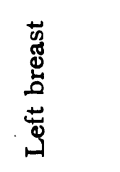 & $\begin{array}{l}\text { 范 } \\
\text {. } \\
\text { ص. }\end{array}$ & 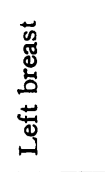 \\
\hline \multirow[t]{2}{*}{ 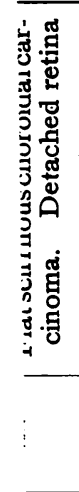 } & 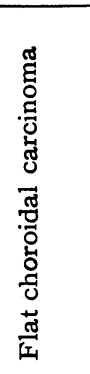 & 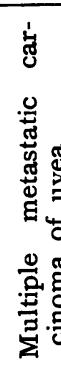 & 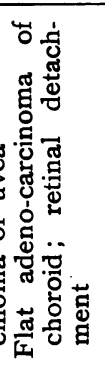 & 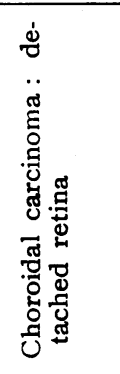 & 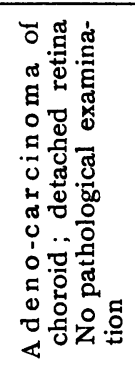 & 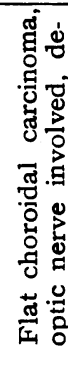 & 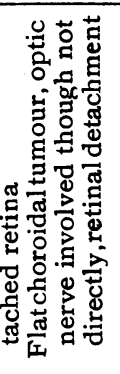 & 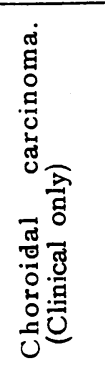 & 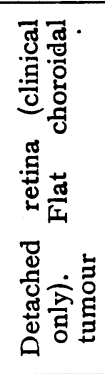 \\
\hline & 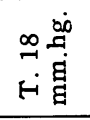 & 1 & $\begin{array}{l}\mp \\
H\end{array}$ & 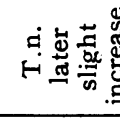 & $\underset{H}{\stackrel{4}{+}}$ & $\stackrel{+}{+}$ & $\stackrel{+}{+}$ & 1 & 1 \\
\hline 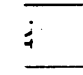 & $\dot{i}$ & $\dot{H}$ & $\dot{x}$ & 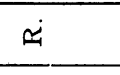 & نـ نهم نهم & هُ & i & ن & $i$ \\
\hline$\therefore$ & กี & 암 & 요 & t & o 1 & 1 & $\ddot{m}$ & $\stackrel{్}{m}$ & n \\
\hline$i$ & $\dot{\Sigma}$ & 庄 & ⿷匚 & 应 & 庄 庄 & 庄 & 庄 & Li & Fi \\
\hline
\end{tabular}

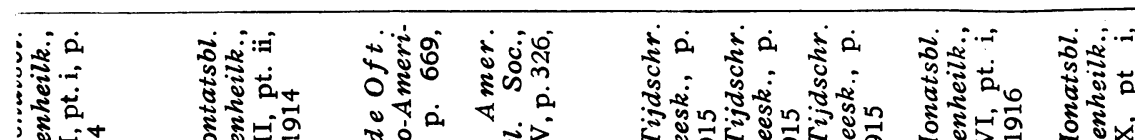
है गं

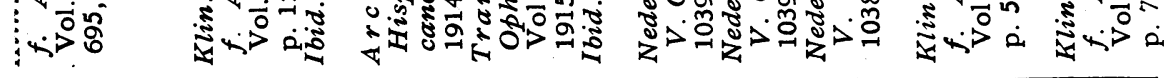

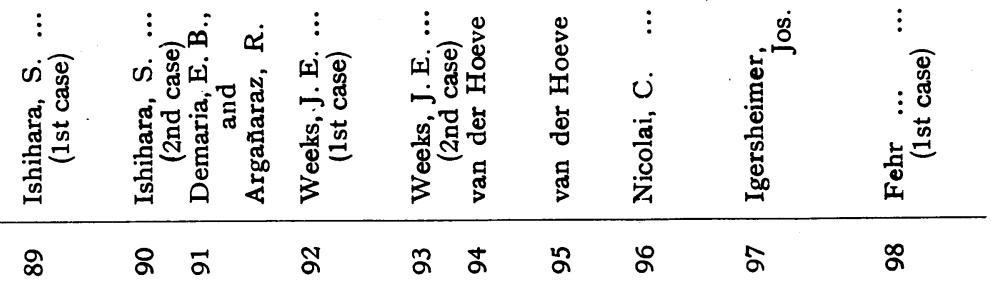


The British Journal of Ophthalmology

\begin{tabular}{|c|c|c|c|c|c|c|c|}
\hline 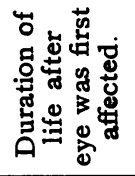 & 1 & 1 & 1 & $\begin{array}{l}\text { 营 } \\
\text { : } \\
0 \\
\end{array}$ & 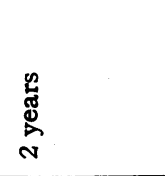 & 1 & 它 \\
\hline 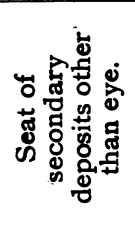 & 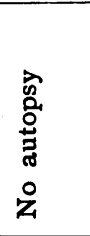 & 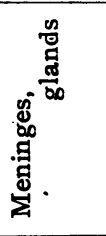 & 1 & 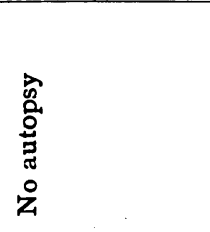 & 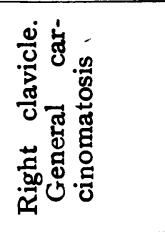 & 邑 & $\begin{array}{l}\vec{\omega} \\
\text { 믐 }\end{array}$ \\
\hline 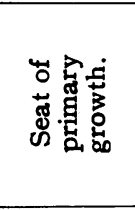 & 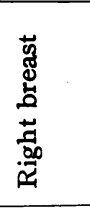 & 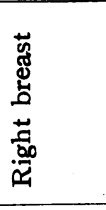 & 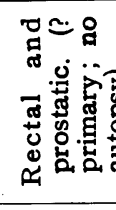 & 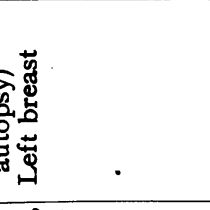 & 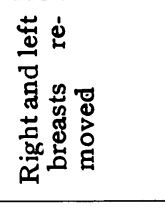 & $\begin{array}{l}\text { 茑 } \\
\text { 由 } \\
\text { m }\end{array}$ & 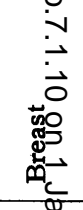 \\
\hline 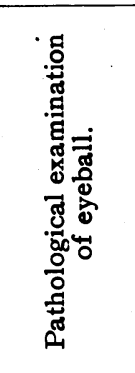 & 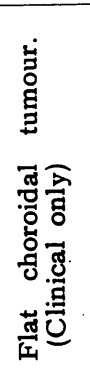 & 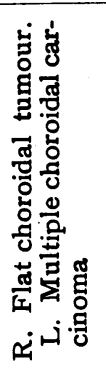 & 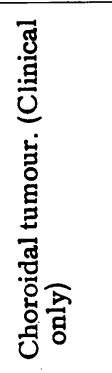 & 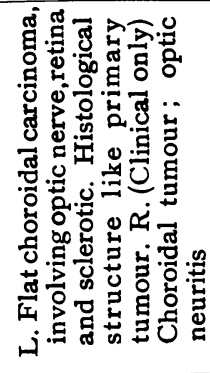 & 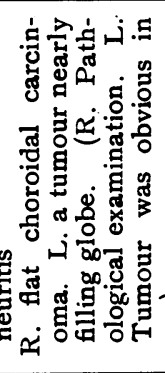 & 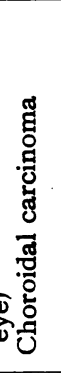 & 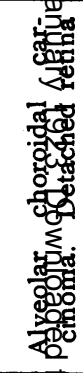 \\
\hline 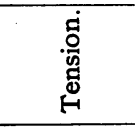 & 1 & 11 & 1 & $\underset{H}{\stackrel{\Xi}{\Xi}}$ & $+\underset{\dot{R}}{\dot{a}}$ & 1 & 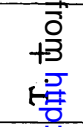 \\
\hline نة نهم & هં & نَـ نهم & ن & ند & نديمه & $\dot{~}$ & $\frac{5}{0}$ \\
\hline $\begin{array}{l}\dot{0} \\
\dot{\alpha} \\
\dot{\alpha}\end{array}$ & \& & th & in & 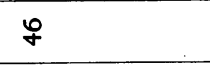 & กี & $\stackrel{ \pm}{N}$ & ñ \\
\hline 离 & 江 & I i & $\dot{\Sigma}$ & 江 & 沽 & $\dot{\Sigma}$ & 现 \\
\hline 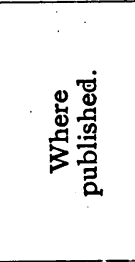 & : & : & : & 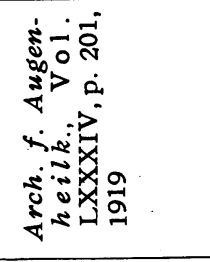 & 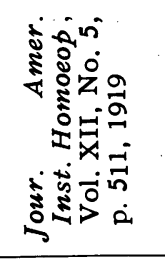 & & 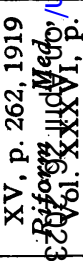 \\
\hline $\begin{array}{l}\text { 总 } \\
\text { 采 }\end{array}$ & 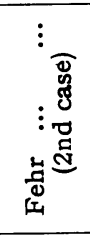 & 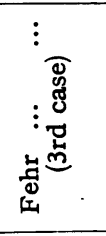 & 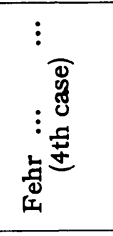 & 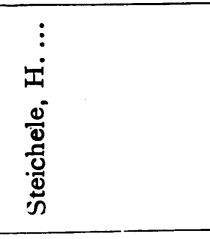 & 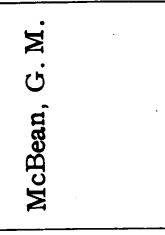 & 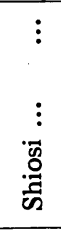 & 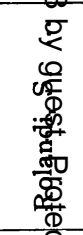 \\
\hline 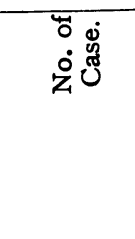 & 2 & 8 & 음 & న్ & 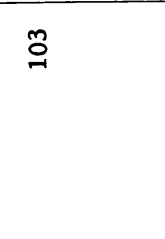 & ర్త & $\stackrel{8}{2}$ \\
\hline
\end{tabular}


Metastatic Carcinoma of the "Choroid and Iris 53

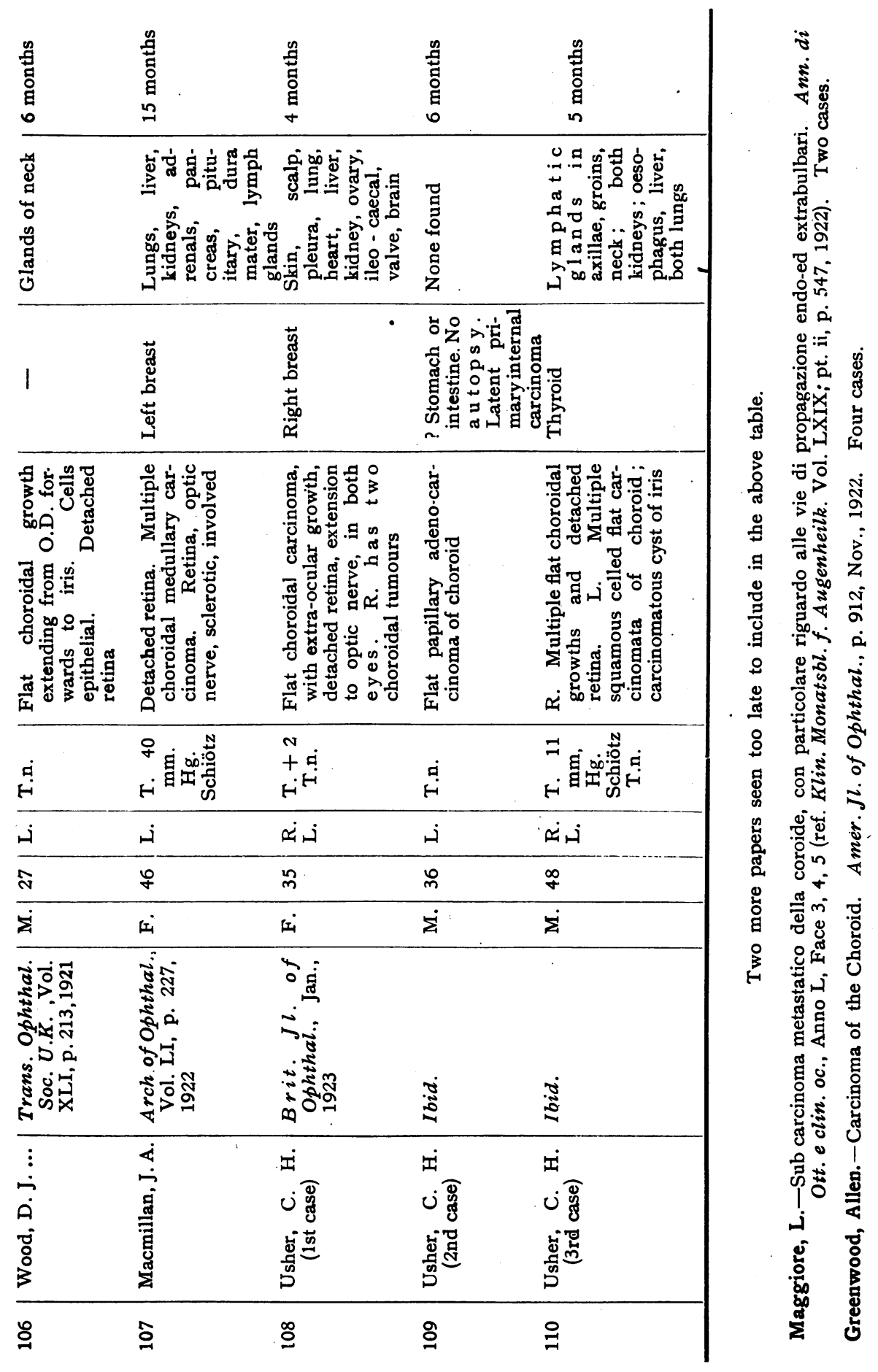


1. Lagleyze.-Archivos de oftalmologia Hispano-Americanos, 1914.

2. van der Hoeve. - Nederl. Tijdschr. v. Geneesk., I9I 5.

3. Arisawa, U.- "Metastatisches Aderhautkarzinom bei latentem Primärtumor." Klin. Monatsbl. f. Augenheilk., Vol. LII, I, p. 695, 1914.

4. Swanzy and Werner.- "Diseases of the lye." Ioth ed., rgr 2.

5. Arisawa. _ "Bericht Ophth. Soc., Heidelberg." Vol. XXXIX, p. 338, I913.

6. Fehr. - "Das Augenspielbild des metastatischen Aderhautcarzinoms." Klin. Monatsbl. f. Augenheilk., Vol. LX, I, p. 74I, I9I8.

7. Oatman, E. L. - "Metastatic carcinoma of the choroid, with report of a case and review of the literature." Amer. Jl. Med. Sciences, Vol. CXXV, p. 375, 1903.

8. Uhthoff, W. - "Zur Lehre vom metastatischen Aderhautcarcinom." Bericht ü 33 oph. Gesellschaft, Heidelberg, I906, p. 193, Wiesbaden, 1907.

o. Gayet.-Arch. d'Ophtal., p. 2 I I, 1889.

10. Kamocki. - Centralbl. f. Augenheilk., p 407, 1884, and Arch. of Ophthal., t. 23, f. I and 2, p. 105, 1894 .

I I. Gelpke, T.-Klin. Monatsbl. f. Augenheilk., Vol. XLIII, I, p. 492, 1905.

12. Reis.-Klin. Monatsbl. $f$. Aus enheilk., 4I, Vol. 2, p. 422, IgO3.

13. Paul. - Arch. f. Augenheilk., Vol. LIII, p. I, I905.

14. Oatman. - Loc. cit.

15. Osler and McCrae.-_" Principles and Practice of Medicine." 9th ed., p. 49I, I920.

16. Finlay, D. W. - The Quarterly Journal of viedicine, Vol. V, p. 524, I9I I-I 2.

17. Macmillan.-Arch. of Ophthal., Vol. 1.I, p. 227, 1922.

18. Michel, V.-Zeitschr. f. Aughenheilk., Vol. XIV, p. 42 I, 1905.

19. Parsons.-_" "Pathology of the Eye." Vol. II, p. 54I.

20. Ewing.-Arch.f. Ophthal., Vol. XXXVI, p. $120,1890$.

2I. Lagrange. - "Tumeurs de l'oeil." Vol. I, p. 512, I90I.

22. Briehn. - "Inaugural-Dissertation, Königsberg, I902.

23. Cutler.-- Trans. Amer. Ophthal. Soc., Vol. X, pt. I, p. 45 I, 1903.

24. Paul. -Arch. f. Augenheilk., Vol. LIII, p. I, I905.

25. Chiarini.-Boll. R. Acc. Med. di Roma., Vol. XXXII, 1907. Ref. Centralbl. $f$ Augenheilk., Vol. XXXI, p. 447, 1907.

26. Proctor and Verhoeff. - Archiv. of Ophthal., Vol. XXXVI, p. 47, I907.

27. Toulant. - Arch. d'Ophtal., Vol. XXXV, p. 44, 1916.

28. Brewitt.-Inaugural-Dissertation, Goettingen, 1903.

29. Ishihara.-Klin. Monatsbi. f. Augenheilk., Vol. II, p. 127, I914.

30. Hippel, v.-Klin. Monatsbi. f. Augenheilk., Vol. I, p. 743, I9I I.

31. Abelsdorff.-Arch. f. Augenheilk., Vol. XXXIII, p. 34, I896.

32. Chance. - Trans. Amer. Ophthal. Soc., Vol. XI, pt. I, p. I78, 1906.

\section{ANNOTATIONS}

\section{The International Congress of Ophthalmology (1925)}

At the International Congress of Ophthalmology held in Washington in April, 1922, Mr. Treacher Collins presented an invitation on behalf of all the Ophthalmological Societies of Great Britain and Ireland to hold the next Congress in London in the year 1925. The invitation was accepted on the motion of Professor Gullstrand, of Upsala, Sweden, seconded by Dr. Lucien Howe, of Buffalo, New York. A general committee consisting of representatives of the inviting Societies has since met and has formed an executive committee, empowered to make arrangements for the 1925 Congress. It is to be held in London during the four days, Tuesday, July 21 to Friday, July 24 . The three official languages are to be English, French and German. The subscription for membership has been fixed at the sum of $£ 2$. Invitations will be sent to the principal Ophthalmological Societies or other 